\title{
LOS JUEGOS DE ROL EN EL AULA
}

Resumen: Las investigaciones realizadas en el ámbito de los juegos de rol y su influencia sobre las mentes de los jóvenes arrojan resultados positivos, es decir, no son peligrosos. Al mismo tiempo, los escasos artículos sobre juegos de rol y educación muestran referencias positivas sobre sus efectos educativos. Sin embargo, los juegos de rol como tales no parecen ser relevantes actualmente como estrategia en Educación Secundaria. El presente artículo hace un repaso de las aportaciones existentes y realiza algunas propuestas sobre su posible aplicación.

Palabras clave: juego de rol; educación secundaria; educación en valores. 


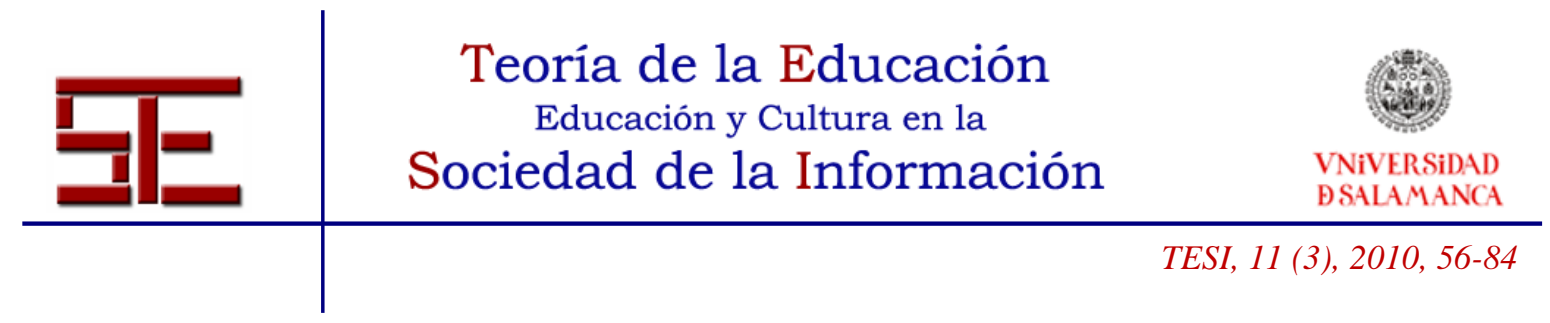

\section{ROLE PLAYING GAMES IN THE CLASSROOM}

Abstract: Research done on the field of role playing games and their influence on young people's minds produces possitive results, that is to say, they (such games) are not dangerous. At the same time, the few articles about role playing games and education show some possitive references about their educational effects. However, role playing games, considered as games, seem not to be relevant as some kind of strategy at Secondary Education nowadays. This article sums up the existing contributions and gives some proposals about their possible implementation.

Key words: role playing games; secundary school; citizenship education

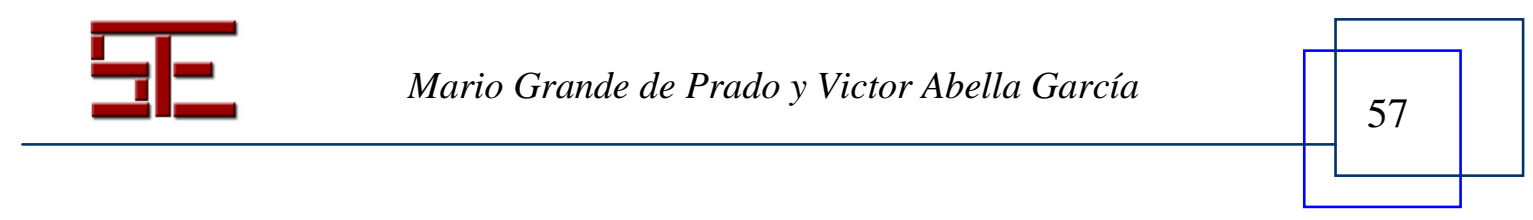




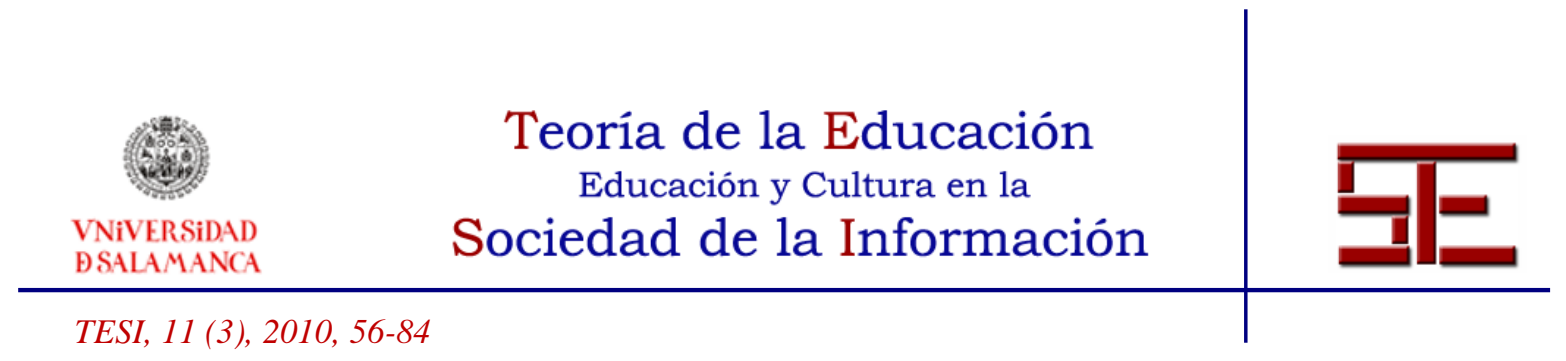

\title{
LOS JUEGOS DE ROL EN EL AULA
}

Fecha de recepción: 22/06/2010; fecha de aceptación: 11/09/2010; fecha de publicación: 30/11/2010

\author{
Mario Grande de Prado \\ mario.grande@unileon.es \\ Universidad de León \\ Víctor Abella García \\ victorabella@gmail.com \\ Universidad de Burgos
}

\section{1.- INTRODUCCION: JUEGOS DE ROL Y PELIGRO}

Los juegos de rol parecen tener (o tienen que padecer) una mala prensa realmente llamativa. Muchos profesores o los mismos alumnos miran con recelo a los alumnos que juegan a rol, los cuales parecen adoptar en ocasiones una cierta actitud de sabia discreción evitando tener que dar explicaciones. En nuestro país todo esto viene derivado de distintos sucesos entre los que destaca el denominado "Crimen del Rol" ocurrido en 1994, en el que dos jóvenes asesinaron a un hombre que encontraron en la calle, y que junto a otros desafortunados eventos atribuidos falsamente a estos juegos han creado una imagen de los juegos de rol como algo peligroso y poco recomendable (Tizón, 2006, 34-42). John Allen Paulos (Paulos, 1988) en una obra sobre analfabetismo matemático, emplea una polémica surgida en EE.UU. sobre la relación entre juegos de rol y suicidios como un ejemplo de una falacia de base amplia en matemáticas, al citarse sólo números absolutos de suicidios sin relacionarlos con la totalidad de la población del grupo de jugadores. Realizando el análisis correcto, se llegaría estadísticamente a que la tasa de suicidio es diez veces menor a la media estadounidense.

En España, algunos conocedores de lo que realmente era un juego de rol expresaron su opinión en distintos manifiestos defendiendo esta afición, destacando por lo conocido de su figura, Pérez Reverte, que afirma:

El juego de rol como tal, avanzado, consiste en un universo alternativo creado por la imaginación, donde la inteligencia, la inventiva, la capacidad de improvisación,

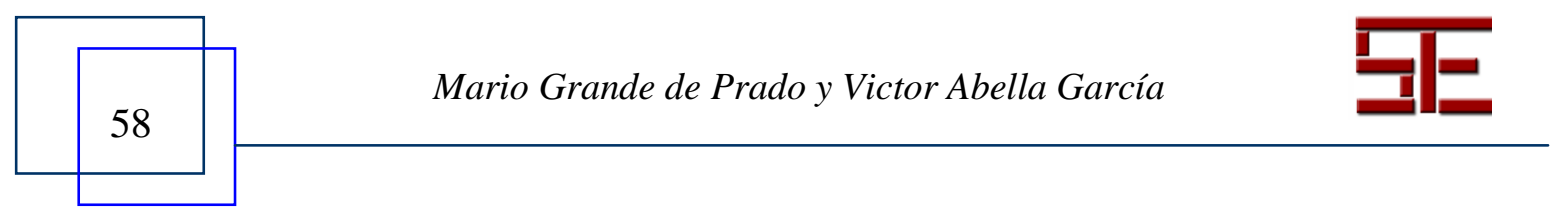




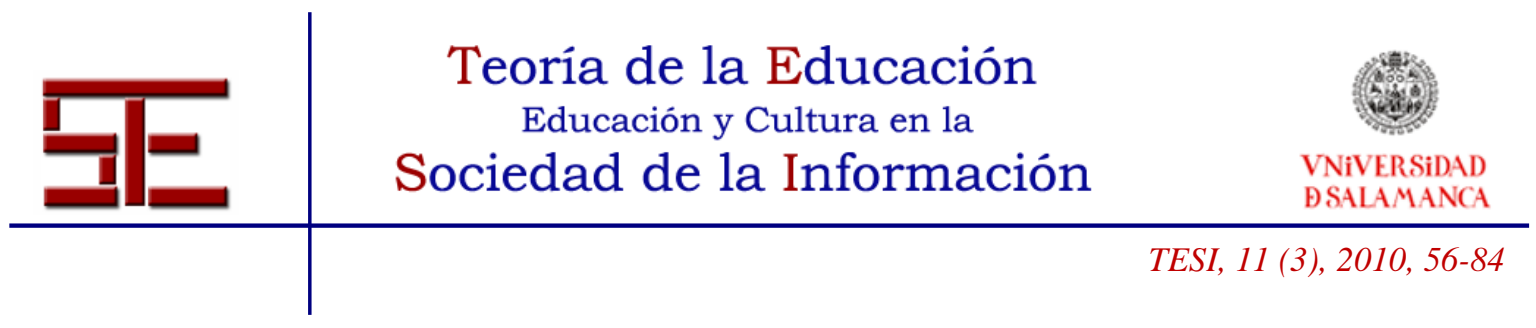

son fundamentales. Los juegos de rol bien planteados y dirigidos estimulan, educan y permiten ejercitar facultades que en la vida real quedan coartadas u oprimidas por el entorno y las circunstancias. La práctica de los juegos de rol proporciona a menudo aprendizaje, destreza, y una legítima evasión muy parecida a la felicidad. (Pérez

Reverte, 1994)

Distintos artículos de prensa demonizaron en su momento los juegos de rol (JdR), mientras que autores, asociaciones y editoriales publicaron diversos comunicados defendiéndolos (muchos de ellos recopilados en páginas webs como En defensa de los juegos de rol http://dreamers.com/defensadelrol/).

Sin embargo, dejando las opiniones de unos y otros aparte, pocos estudios se han realizado en nuestro país sobre los juegos de rol.

Probablemente, uno de los más interesantes por su rigor, imparcialidad y por la amplitud de la muestra, es el realizado por el Colegio Oficial de Psicólogos de Madrid en el año 1999 a instancias del Defensor del Menor de Madrid (VV.AA., 1999). Con el título Efectos psicosociales de los juegos de rol en el desarrollo social y cognitivo de los menores, sus objetivos eran:

- Comprobar si existen diferencias en el desarrollo social y cognitivo entre jugadores de rol y no jugadores.

- Comprobar si existen diferencias en el desarrollo social y cognitivo de los jugadores de rol menores de edad, en base a su afición a estos juegos.

Sus conclusiones se resumen en:

los resultados obtenidos en este estudio permiten concluir que el desarrollo social y cognitivo de los adolescentes que juegan al rol es similar al que presentan los menores que no practican este tipo de juegos, ya que la variable Juego de rol no influye en ninguna de las variables que miden dicho desarrollo. Únicamente puede constatarse

una excepción en el caso de las mujeres, donde parece que jugar al rol influye positivamente, reduciendo la ansiedad social y la timidez. (VV.AA., 1999).

El resto de estudios serios que existen son anglosajones (Tizón, 2006, 161-163) en su mayor parte, y ofrecen unos resultados similares a los nacionales, con lo que, ciñéndonos a la investigación y a la ciencia, los juegos de rol son, por tanto, no peligrosos ${ }^{1}$.

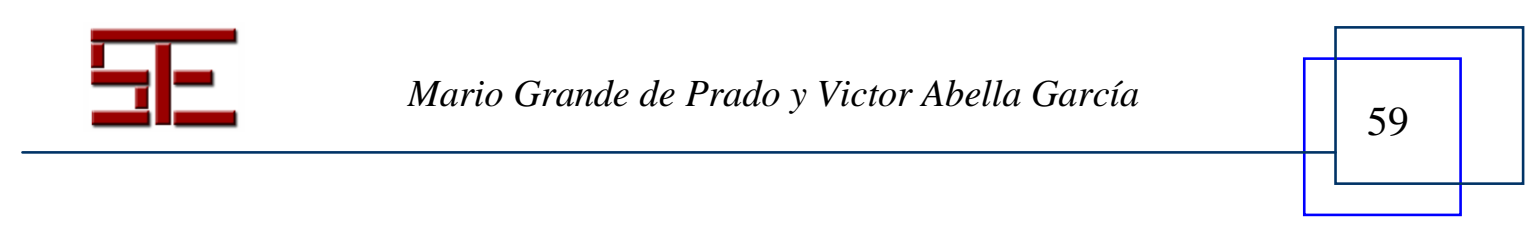




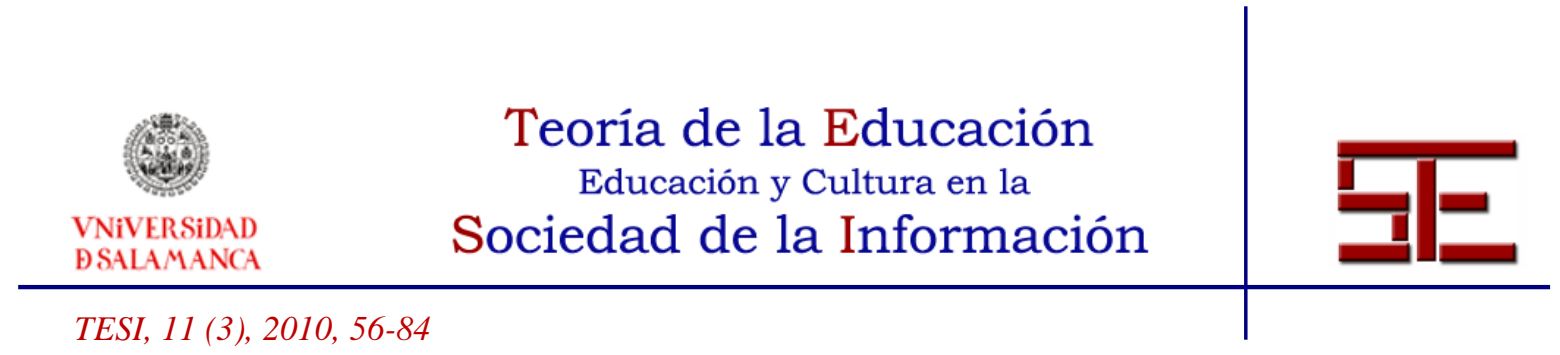

\section{2.- JUEGOS DE ROL Y EDUCACIÓN}

Ahora que ya tenemos como base que este tipo de juego no es pernicioso, vamos a analizar hasta qué punto pueden ser útiles a nivel educativo.

Antes de empezar, es importante señalar uno de los aspectos más relevantes en la sociedad actual: los cambios que la transforman y que van a suponer retos, especialmente para las nuevas generaciones.

Nuestro mundo está cambiando (siempre ha cambiado), pero en nuestro momento histórico, a una velocidad acelerada por el avance de las TIC (tecnologías de la información y la comunicación). La relevancia de las instituciones educativas en nuestra sociedad se fundamenta en que los conocimientos cambian tan rápido que tenemos que reciclar y renovarnos cada poco tiempo. Esto obliga a replantearnos la intervención educativa (Cantón, 2001).

Las TIC constituyen una auténtica revolución que supera ampliamente por su inmediatez y globalización referentes anteriores como la invención de la escritura, la imprenta o la revolución industrial. Las TIC, representadas por Internet como eje vertebrador recorren el planeta rápidamente y sus efectos se multiplican debido a que en este nuevo mundo los receptores pueden transformarse en emisores sin una dificultad ni un coste alto. Castell (2001) afirma que la irrupción de las tecnologías de la información y la comunicación en nuestras sociedades modelan una nueva forma de entender la cultura, en la que la información es el elemento clave de esta sociedad.

Una idea, un texto o una imagen se difunden en Internet, para, en cuestión de horas, ser comentado, modificado o satirizado por cualquiera con conexión y mediante servicios gratuitos como blogs, foros o servicios multimedia como el omnipresente Youtube. Dicho de otra forma, los cambios son rápidos, ramificados, multidireccionales... y la información, pieza clave de esta nueva sociedad, debe ser transformada en conocimiento y para ello, digerida, masticada, vivida. Desde un punto de vista socioeconómico, el conocimiento, que implica acceso a la información, capacidad de comunicación y reflexión, es el elemento clave para la generación de riqueza en el nuevo orden mundial (Castell, 1997). La escuela, por tanto, debe aportar los recursos necesarios para que el alumno aprenda a adaptarse a este entorno en constante cambio y estrategias para tratar la información, que puede llegar a desbordarnos. Los juegos de rol, en ese sentido, constituyen una estrategia interesante para llegar a convertir en conocimiento los datos y la información.

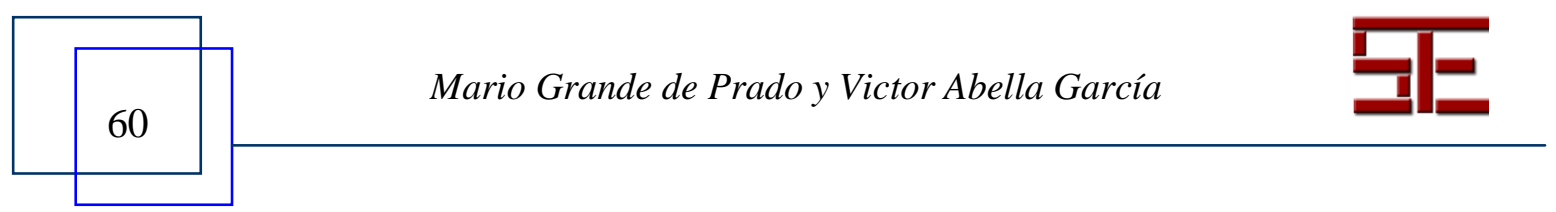




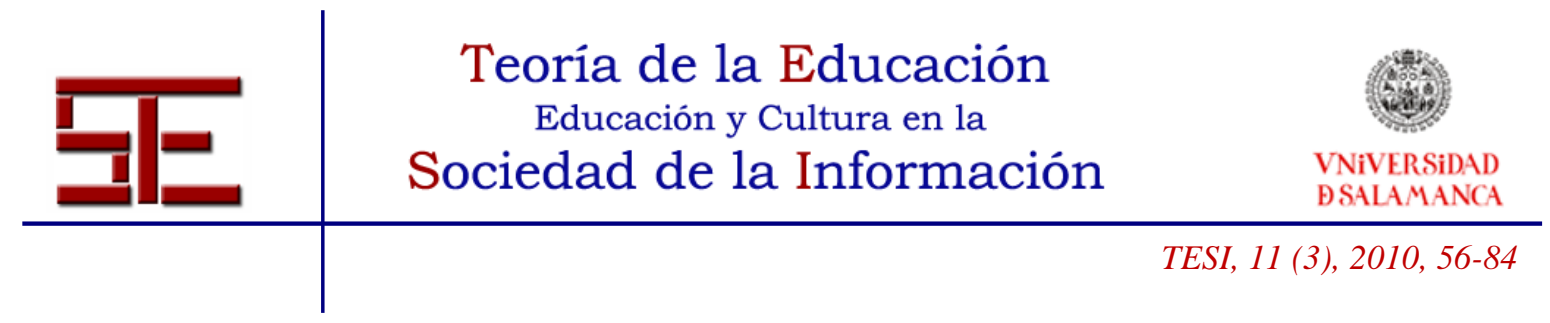

Centrándonos nuevamente en la utilidad de los juegos de rol en la educación, la bibliografía al respecto no ha sido especialmente amplia en este caso, pero es importante señalar que en los últimos años están surgiendo un número mayor de iniciativas.

Destaca por su oficialidad la página del MEC

http://www.isftic.mepsyd.es/w3/recursos2/estudiantes/ocio/op_03.htm\#03

Esta página en buena parte reproduce el artículo "Los Juegos de Rol: Hacia una propuesta pedagógica" de Pablo Giménez en el que se indican los beneficios educativos de los JdR:

Tabla 1.- Síntesis de los beneficios de los juegos de rol. Fuente: MEC / Pablo Giménez

\begin{tabular}{|l|}
\hline Beneficios en la educación: \\
\hline Permite acceder al conocimiento de forma significativa \\
\hline Útil para memorizar \\
\hline Mejorar el empleo del cálculo mental \\
\hline Promoción de la lectura como medio lúdico y recreativo \\
\hline Gran riqueza de vocabulario \\
\hline \\
\hline Aportación a determinadas actitudes: \\
\hline Al desarrollo de la empatía y la tolerancia \\
\hline A la socialización \\
\hline \\
\hline Aportación para un buen estado de salud mental : \\
\hline $\begin{array}{l}\text { (incluso se cita un estudio americano en el que se señala que existe una menor } \\
\text { tendencia al suicidio entre los jugadores de JdR) }\end{array}$ \\
\hline
\end{tabular}

En otro artículo, en Cuadernos de Pedagogía, $\mathrm{N}^{\mathrm{o}} 285$, Joan Ortiz Castells defiende los juegos de rol como una vía lícita de aprendizaje y cita varios valores de los juegos de rol en contraposición a los de la institución educativa.

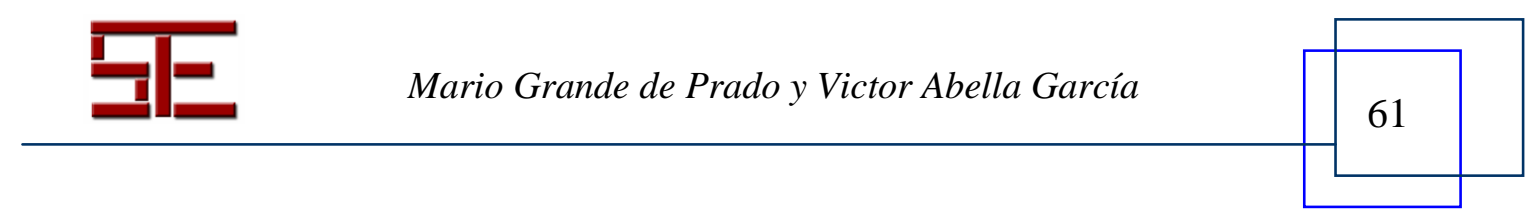




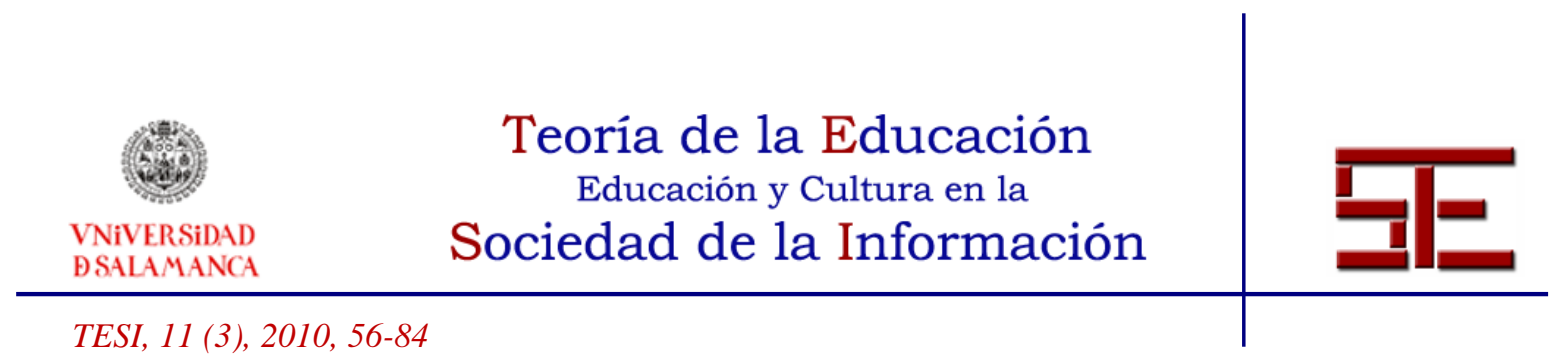

Tabla 2.- Comparativa entre la escuela tradicional y los juegos de rol (sintetizado y resumido de Ortiz, 1999)

\begin{tabular}{|c|c|}
\hline ESCUELA TRADICIONAL & JUEGO DE ROL \\
\hline Actividad formal & Lúdica \\
\hline Obligatoria & Voluntaria \\
\hline Racionalidad y racionalismo & Mito y fantasía \\
\hline Motivación externa & Automotivación \\
\hline Conocimientos fraccionados & Conocimientos globalizados \\
\hline Imita y copia conocimientos & $\begin{array}{l}\text { Creatividad y construcción de significados } \\
\text { nuevos }\end{array}$ \\
\hline Rigidez y autoritarismo & $\begin{array}{|lll|}\begin{array}{l}\text { Autoorganización del conocimiento e } \\
\text { investigación }\end{array} & & \\
\end{array}$ \\
\hline Dogmatismo científico & Pensamiento crítico \\
\hline Grandes hechos & \begin{tabular}{|l}
$\begin{array}{l}\text { Concede importancia a pequeñas } \\
\text { informaciones }\end{array}$ \\
\end{tabular} \\
\hline Lecturas obligadas & Motivación para la lectura \\
\hline Memorización forzada & Memorización voluntaria \\
\hline $\begin{array}{l}\text { El profesorado no tiene tiempo para } \\
\text { interactuar }\end{array}$ & Interacción entre compañeros \\
\hline Baja comunicación & Potencia diálogo \\
\hline Competitividad & Colaboración \\
\hline Trabajo individual & Trabajo colectivo \\
\hline Valores teóricos & $\begin{array}{l}\text { Valores vividos: empatía, tolerancia, toma } \\
\text { de decisiones y responsabilidad... }\end{array}$ \\
\hline Anónimo y uniforme & Autoafirmación personal \\
\hline Formación para el futuro & Formación "just in time" \\
\hline Motivación externa & Incentivación para aprender a aprender \\
\hline Inseguridad y frustración & Seguridad y autoestima \\
\hline Sensación de aprender cosas inservibles & De respuesta a necesidades afectivas \\
\hline Clases coercitivas & Libertad de movimientos y expresión \\
\hline Angustia & Terapéutico, liberador de tensión \\
\hline Centrado en el pasado & Vivencias anticipadoras \\
\hline Uniformidad & Multiculturalidad \\
\hline
\end{tabular}

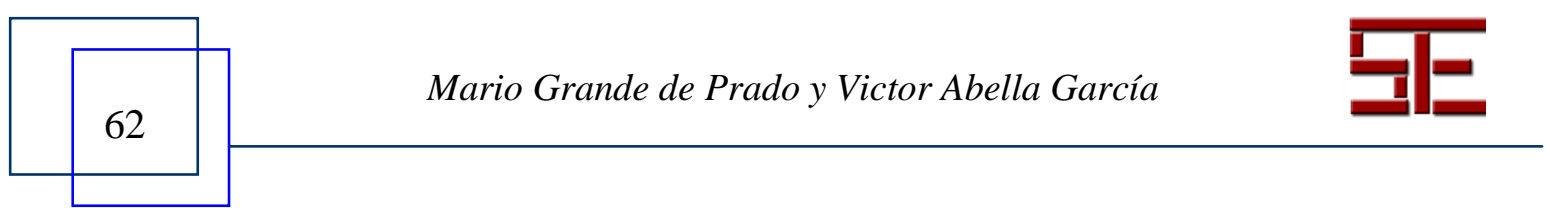




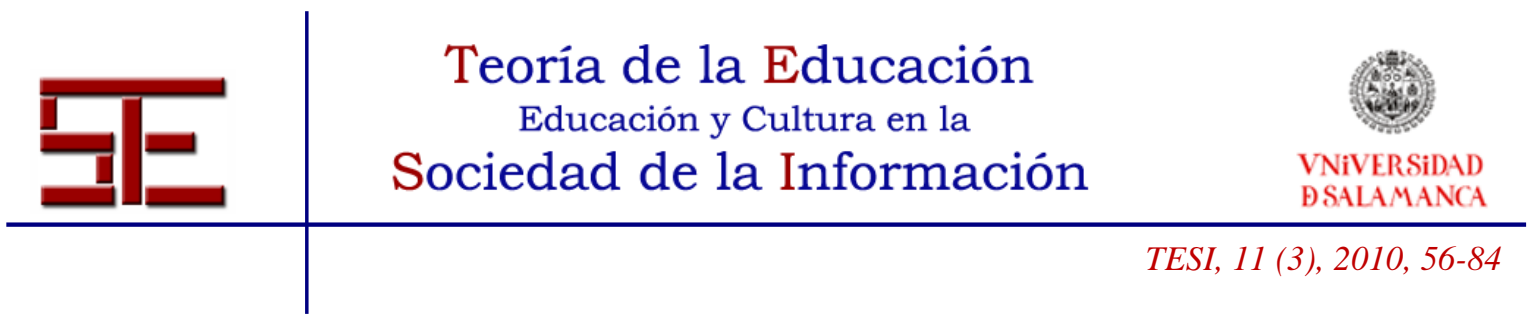

No podemos dejar de citar una de las primeras aportaciones sobre juegos de rol y educación, en este caso centrándose en sus posibilidades hacia el fomento de la lectura y la literatura, emparentándolos con los Cuentacuentos tradicionales (Calleja, 1995). Por supuesto, la relación entre juegos de rol e historia es evidente (basta con ambientar las partidas o sesiones de juego en entornos históricos bien documentados). En los aspectos relacionados con los valores, se realiza un comentario más extenso en otro de los apartados de este artículo.

Una de las aportaciones más recientes e interesantes por lo práctico, la aporta la revista Tándem cuyo número 34 (2010) es un monográfico dedicado a los juegos de rol en vivo, analizando el uso del juego de rol en vivo como herramienta didáctica.

\section{3.- JUEGOS DE ROLES Y JUEGOS DE ROL}

Algunas veces la literatura educativa mezcla los juegos de rol en vivo y los juegos de rol ( $\mathrm{JdR}$, en inglés roleplaying games) con juegos de roles (role play o roleplaying). Estos últimos son deudores de los psicodramas de Moreno (Tizón, 2006) y son una estrategia didáctica con amplia base en la educación en valores (VV.AA., 2008).

Los juegos de roles tienen algunas similitudes y diferencias con los juegos de rol que pasamos a analizar:

Similitudes entre los juegos de rol y los juegos de roles

* Existe una simulación en la que se interpreta un papel

* No existe un guión cerrado, los participantes actúan en base a sus deseos y lo que consideran que haría su personaje

* Suele existir un moderador imparcial, el director de juego o moderador.

Diferencias entre juegos de roles y juegos de rol en vivo, en comparación con los jugos de rol:

* En los juegos de roles, el objetivo es didáctico, para sensibilizar, empatizar o comprender, en los JdR el objetivo es el entretenimiento.

* En los juegos de roles y en los juegos de rol en vivo, se suele representar una escena, un momento puntual, por ejemplo, en la "Autopista del Prado verde" los

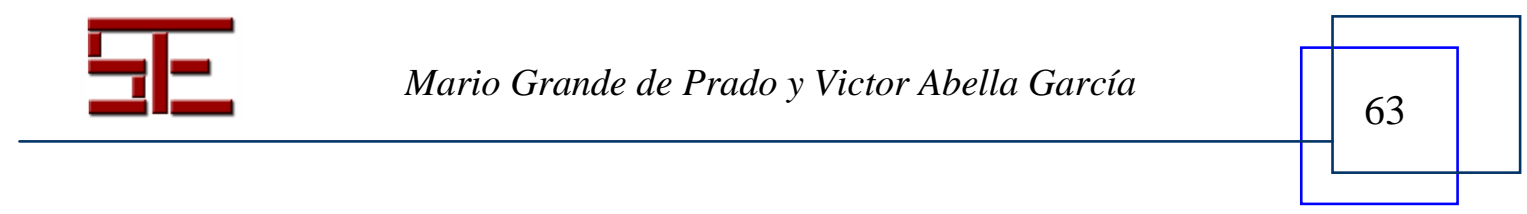




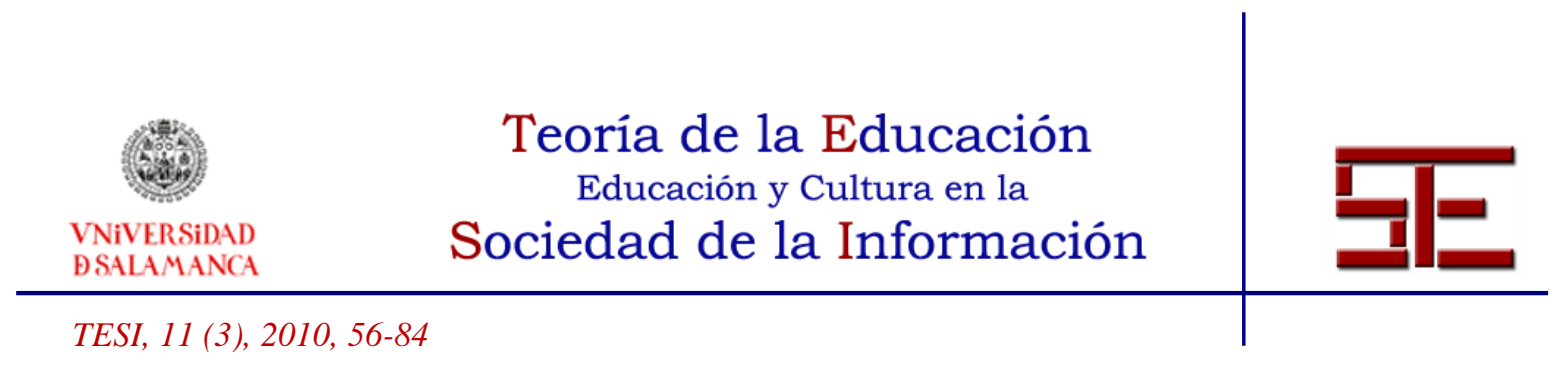

participantes representan a los implicados en la construcción de una autopista reunidos por el Ayuntamiento para debatir el tema). En los JdR se suelen interpretar situaciones más amplias. En el caso anterior, el debate podría formar parte de una partida, pero sería sólo una más dentro de la "película".

* Los personajes en los JdR pueden emplearse en varias sesiones de juego, mientras que en los juegos de roles sólo se suelen utilizar una vez. Además, en los primeros suelen estar más perfilados a nivel de destrezas, conocimientos...

* Los JdR suelen describir una ambientación o mundo de juego, con unas reglas y un estilo de juego (traen información para jugar por ejemplo en el universo de Star Wars) y permiten que los directores de juego ${ }^{2}$ creen sus propias aventuras o dirijan aventuras ya hechas por editoriales o aficionados. Por el contrario, los juegos de roles sólo reflejan una escena a jugar (siguiendo el símil de Star Wars sería como si sólo permitiesen jugar una escena).

Como parece evidente, la diferencia si es que existe) entre juegos de rol en vivo y juegos de roles en vivo facilitan la utilización de los juegos de roles en el aula al ser breves y requerir menos preparación. Suelen suponer una mayor facilidad para implicar a grupos amplios, mientras que los juegos de rol tradicionales están destinados normalmente a grupos de entre 2 a 6 jugadores.

Los juegos de roles aparecen citados como recursos interesantes en Estrategias didácticas (Bañeres, 2008), con un pequeño capítulo dedicado a ellos en el que se incide en dinámicas relacionadas con Educación para la Salud ("K-1000" y "Lidia"). En programas de convivencia también existen distintos juegos de roles (Muñoz, 2003) y también nos encontramos con numerosas actividades de simulación relacionadas con la educación ambiental (Taylor, 1995; Krammer, 2002) siendo especialmente destacable por lo extenso y verídico El accidente minero de Aznalcollar (VV.AA., 1999b)

Un tratamiento aparte merece Pasajes, juego de sensibilización (VV.AA., 2001), editado por ACNUR y en el que el azar forma parte de la actividad, y (aquí radica la diferencia con respecto a otros juegos de roles) aparecen descritas varias escenas o situaciones que nos permiten simular una huida familiar desde un país en conflicto (existen iniciativas similares por parte de algunas ONGs).

Recientemente nos encontramos con varios trabajos con propuestas sobre juegos de rol en vivo/ juegos de roles (muchos de ellos en un monográfico excelente de la revista Tándem). Son los siguientes:

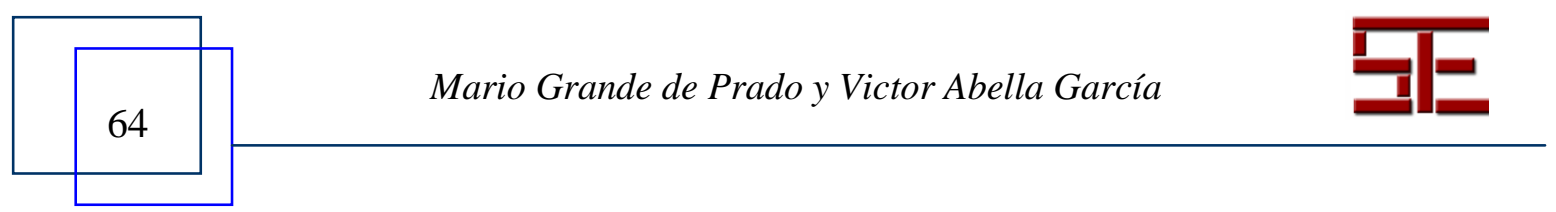




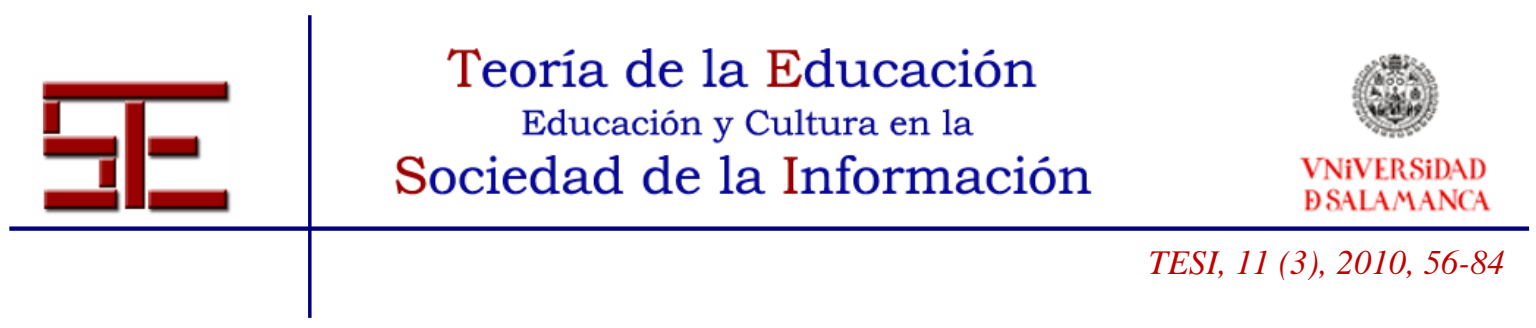

* Sobre educación sexual e identidad de género (Izquierdo, 2010).

* Sobre valores, empleando la temática súper-heroica (Jiménez; Caballero y Tinoco, 2010).

* Para acercarnos al patrimonio histórico-cultural (García; Amarilla y Rovira, 2010).

* Para trabajar conflictos, resolución de problemas (Parra; Caballero y Domínguez, 2010).

* Para trabajar valores como el respeto (VV.AA., 2010).

* Por último, en una propuesta de trabajo sobre educación para la salud, acompañada por un proceso de investigación (Pérez; Delgado y Rivera, 2009), los autores nos muestran que la aplicación de los juegos de rol en vivo en el aula durante un lapso e tiempo significativo importante favorece el aprendizaje significativo del alumno.

A modo de conclusión, podemos ver que la vertiente "en vivo" de los juegos de rol tiene un claro interés didáctico, especialmente en el campo de las actitudes y valores, y que posee una mayor historia y uso del que podría imaginarse a priori.

\section{4.- JUEGOS DE ROL Y ETICA}

La ética es una parte de la Filosofía que nos ayuda a reflexionar sobre lo bueno y lo malo. Un aspecto relacionado con ella son los dilemas morales: situaciones en las que dos valores entran en conflicto y debemos escoger (elegir entre dejar morir a un ser querido o robar, el conocido Dilema de Heinz).

La legislación educativa señala las actitudes y valores como uno de los contenidos educativos (artículo 19 de la LOE) y en la práctica suelen ser uno de los aspectos menos trabajados: es relativamente fácil trabajar conceptos y procedimientos pero no así las actitudes, en las que no todos los profesores se sienten comprometidos de la misma forma, percibiéndolos en muchas ocasiones como muy difíciles de alcanzar o incluso como un intento de adoctrinamiento. (No hay que olvidar la polémica suscitada por la asignatura de Educación para la Ciudadanía).

Muchas veces se intenta llegar a las actitudes a través de la racionalización, trabajando los conceptos, pero eso no implica necesariamente una sensibilización de los alumnos: no es lo mismo aprenderse de memoria los artículos de la Declaración de los Derechos

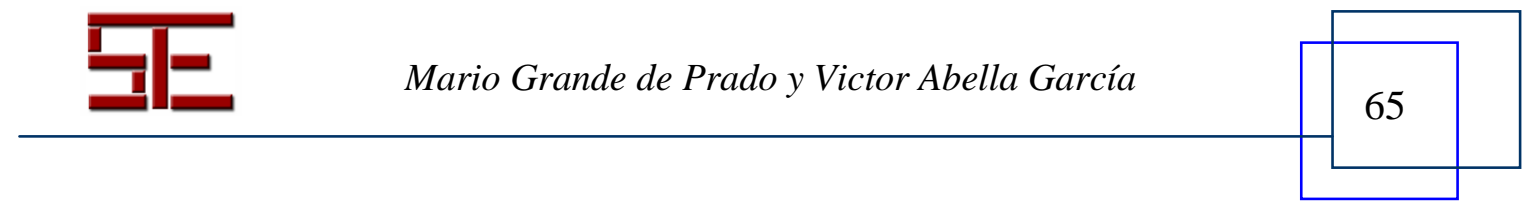




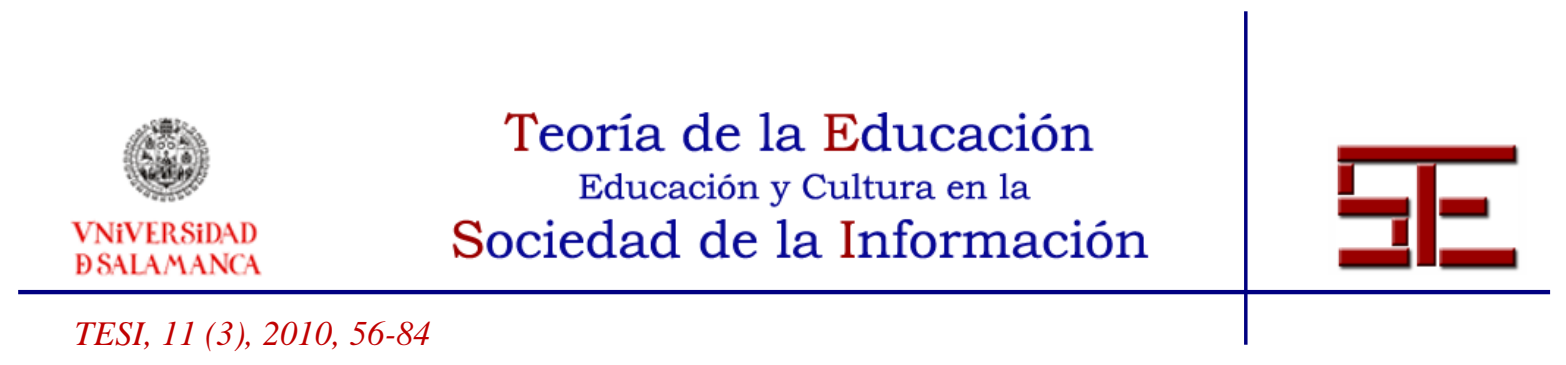

Humanos que reflexionarlos y valorarlos.

Para ello, la Psicología señala que aprendemos más de lo que intencionalmente se nos quiere mostrar por imitación u observación. Lo que se denomina el aprendizaje vicario, que se ve ilustrado por la clásica conducta del padre fumador que le dice a su hijo "no fumes" mientras su hijo está aprendiendo que los adultos fuman, y que si quiere crecer debe fumar.

Por tanto, si queremos un aprendizaje integral, debemos desarrollar competencias desde un aprendizaje significativo de las actitudes y los valores.

Las actitudes y los valores son fenómenos intrapersonales, formados por el sujeto en interacción con el ambiente. Cumplen unas funciones básicas (Rokeach, 1979), que son:

1- interpretan la realidad que rodea

2- son instrumentales, adaptativas o utilitarias

3- expresan los valores

4- crean autoestima

Estas actitudes son predisposiciones positivas hacia lo que da sentido y mantiene la coherencia de nuestra visión de la realidad; y, por el contrario, genera actitudes negativas a lo que pone en peligro su armonía. Esta predisposición es fruto de sus creencias o experiencias ante situaciones concretas. Por tanto se adquieren, y son educables, siendo su base los valores. Y si hablamos de valores, de actitudes, es necesario hablar de las normas. Las normas son pautas de conducta y pueden ser internas o externas.

Las actitudes y las normas se diferencian porque aunque las dos son principios de acción, las normas advierten al sujeto desde fuera o coaccionan su actuación, el individuo las aprende dentro del sistema institucional, y cumpliéndolas se adapta a la sociedad. Las normas intrínsecas se basan en valores.

Los valores, las actitudes y las normas se pueden enseñar, y por esto se pueden aprender desde el momento de nacer, en el proceso de socialización que tiene en primer lugar en los núcleos de socialización primaria: familia, grupos de iguales y escuela, y, en segundo lugar, a través de los grupos secundarios, medios de comunicación, asociaciones, trabajo... Esta enseñanza se realiza en buena parte por vía emocional y por

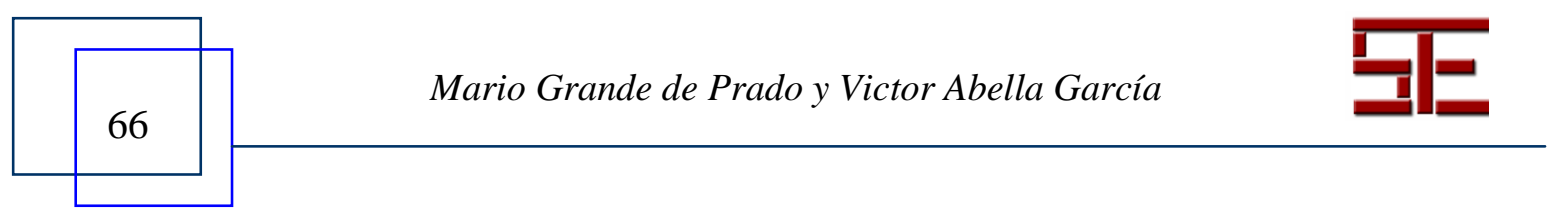




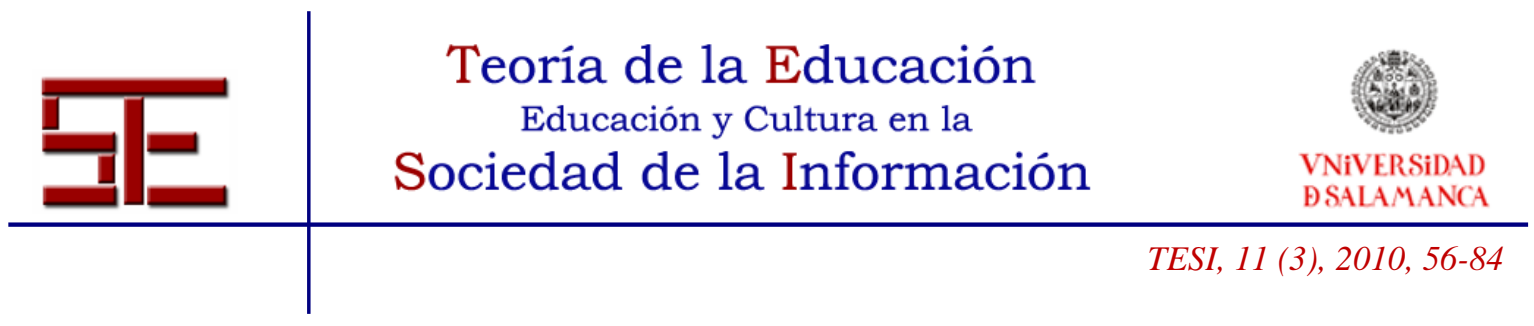

propia experiencia y observación.

\section{5.- JUEGOS DE ROL Y DILEMAS MORALES}

Teniendo en cuenta las definiciones de los JdR, parece apropiado sugerir que la empatía y la observación pueden ser vías de sensibilización, que pueden proponerse desde los juegos de rol. Tal y como dice en su web la ONG Amnistía Cataluña: http://www.amnistiacatalunya.org/:

Características de los juegos de rol relacionadas con actitudes y valores:

-Planteados adecuadamente, favorecen el desarrollo de la empatía y la tolerancia

-En la medida en que no son juegos competitivos e implican la resolución de conflictos, fomentan la socialización y la cooperación.

-Fomentan la toma de conciencia del alcance de las propias decisiones.

Los juegos de rol suponen interpretar, experimentar en cierta forma otros papeles, otras experiencias y, por ello, pueden jugar una importante baza. Los jugadores pueden experimentar, simular e interpretar situaciones ficticias en las que pueden sentir una mayor implicación que con otras dinámicas. Por supuesto pueden interesarnos cuestiones que sean el leit motiv de la historia (o no). Si quiero que mis alumnos experimenten lo que es la discriminación racial o xenofobia, puedo decirles que en EEUU durante mediados del siglo XX existían fuertes limitaciones a los derechos civiles. Como contenido teórico puede ser fagocitado y expulsado durante un examen, pero tal vez se pueden emplear los juegos de rol para plantear algo que sea provechosamente asimilado por la mente del jugador:

Interpretas a John, un joven de color en el estado de Misuri. Trabajas en una zapatería y en general te van bien las cosas. Un día a la vuelta en bici del trabajo observas que un coche te persigue. El coche acelera y te embiste, mareado y confuso ves como salen cuatro figuras ataviadas con la ropa del KuKusKlan. Te intentas levantar y echar a correr....

Y se puede transformar fácilmente en un dilema moral

Eres Harry, un joven blanco que sabe que unos miembros del KKK van a buscar a los chicos negros de la zona. A ti te parece mal, pero algunos del KKK son amigos tuyos de la infancia. Estás dando un paseo y observas cómo embisten a un ciclista negro.

Un dilema moral es una narración breve en la que se plantea una situación posible y

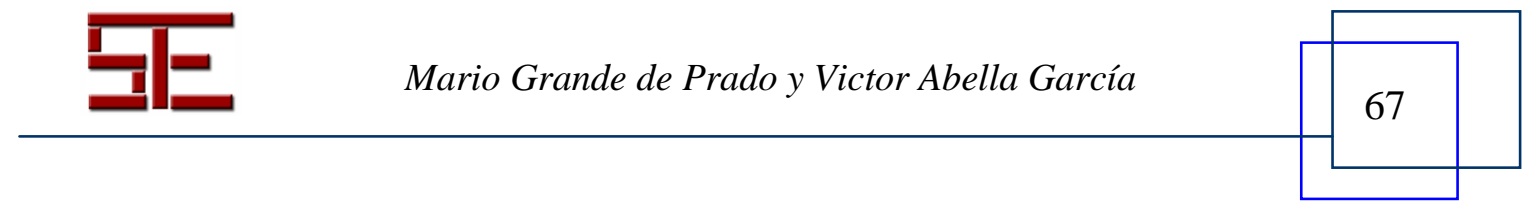




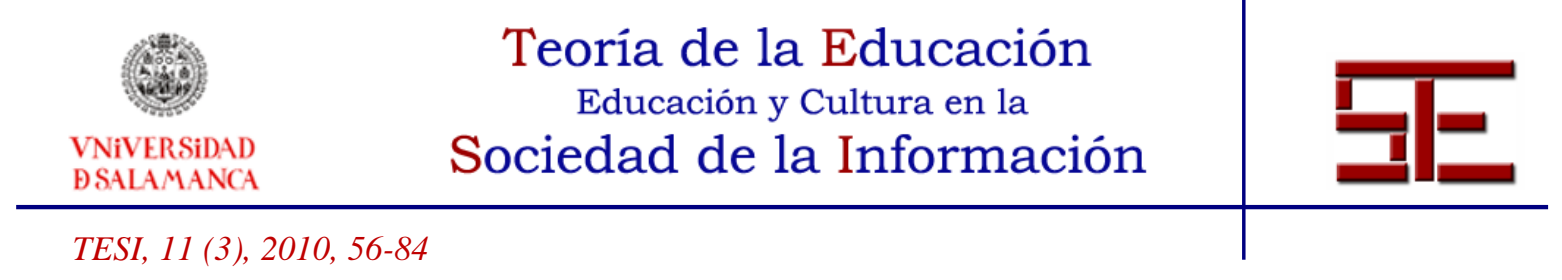

conflictiva a nivel moral, y se solicita o bien una solución razonada o un análisis de la solución elegida por el protagonista. Se presenta normalmente como una elección disyuntiva: el protagonista se encuentra en una situación decisiva ante la cual sólo existen dos, y nada más que dos, opciones, siendo ambas soluciones factibles y defendibles. El individuo se encuentra ante una situación conflictiva. Es curioso constatar los paralelismos que existen entre el uso en el aula de los dilemas morales y los juegos de rol, dado que se pide identificación con los personajes y toma de decisiones.

¿Cómo construir un dilema moral? (y aplicarlo en un juego de rol):

* Evitar dilemas ambiguos, sin palabras excesivamente técnicas, o bien con una historia complicada de entender.

* Que el conflicto moral inicial pueda ser solapado al estar rodeado de otros conflictos más atractivos.

* Evitar que el director de juego aporte las soluciones el problema. (favoreciendo así la autonomía moral de los jugadores).

* Procurar que el jugador aporte las razones de sus acciones en base a la historia de su personaje. En último extremo, la libertad de elección debe ser tenida en cuenta.

Uno de los más conocidos es el dilema propuesto por Kholberg (Kholberg, 1992), «Dilema de Heinz», en el que un hombre debe elegir entre robar un medicamento o dejar morir a su mujer. Lo legal es no robar y dejar morir a su mujer. ¿Pero es lo correcto?

\section{1.- Ejemplos de partidas y dilemas morales}

Además, muchas partidas pueden tratar temas de actualidad (p. ej. la drogadicción y sus efectos) y sus tramas ofrecen en ocasiones moralejas. Por ejemplo, en la partida de terror ambientada en la Gran Guerra La Bestia no debe nacer (Ibáñez, 1989), en el momento final resulta la importancia de los sentimientos positivos sobre los destructivos. En Unidad Beta (Díaz Sacaluga, 2006), una historia de superhéroes en la Segunda Guerra Mundial, se plantea la posibilidad del perdón o del cambio de algunos personajes desde un rol negativo hacia algo más positivo. Y ojo, en ambas aventuras la acción transcurre en conflictos armados, y el director de juego puede mostrar el horror

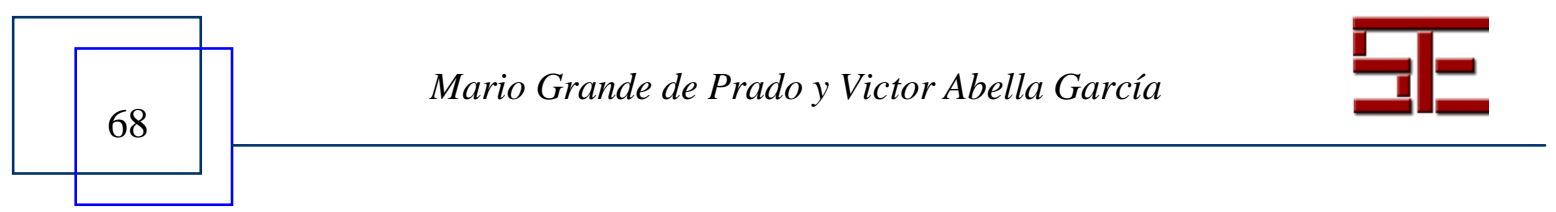




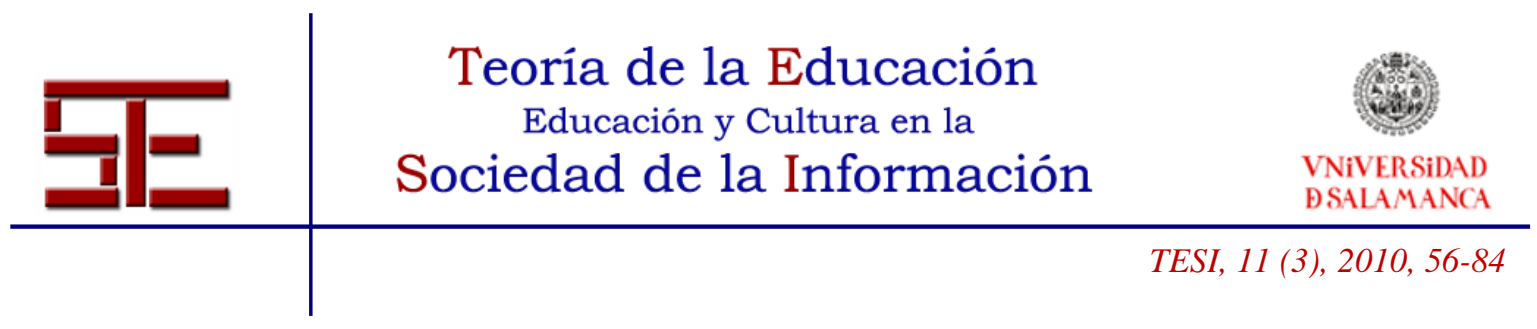

de la guerra y sus consecuencias en los dos bandos. Siguiendo el paralelismo con el cine, las películas de Clint Eastwood Banderas de nuestros padres y Cartas desde Iwo Jima pueden servir como referente para tratar un conflicto desde el punto de vista humano en ambos bandos.

Un juego reciente sobre espionaje, Eyes Only de Pedro J. Ramos (Ramos, 2008), propone algunas ideas interesantes buscando siempre la decisión y el conflicto moral, por ejemplo, situando a niños en conflictos armados, con organizaciones similares a ONGs pero con métodos más expeditivos...

En otras partidas es la lealtad lo que se ve recompensado o la capacidad de sacrificio por los demás. Además, en la mayor parte de los juegos de rol, los personajes son los héroes, los buenos, si bien queda en manos del director de juego ser maniqueo en la dicotomía bien/mal o establecer unos matices de gris (los personajes pueden ser orcos o semiorcos en el Señor de los Anillos con actitudes opuestas a las tradicionales, de hecho existe un juego de rol gratuito que parte de esa curiosa premisa).

\section{2.- Ambientaciones}

Si bien la actualidad puede ser interesante, la ciencia ficción sin duda permite tratar temas morales (e incluso con reflejo actual) desde un mayor distanciamiento. Series como Star Trek, Babylon 5 o Battlestar Galactica 2003 ofrecen, además de efectos especiales, en muchas ocasiones tramas repletas de dilemas morales (la clásica "Primera directiva" en Star Trek que implica no inmiscuirse en el desarrollo de otras sociedades no evolucionadas a nivel técnico). Aunque parece que estoy planteando algo totalmente ajeno a la realidad, los principales implicados en Galactica fueron invitados a la ONU (17 de marzo de 2009, disponible online en la página web de la ONU) debido al interés sobres aspectos morales que aparecen en la serie. Y el productor y guionista de esa serie, Ronald D. Moore, es uno de los implicados en las series de los 90 de la franquicia Star Trek (donde los aspectos morales resultaban relevantes en más de una ocasión.

Todo esto nos lleva a una comparativa entre los propios puntos de vista, los de los demás, los de un personaje diferente, culturas históricas con diferentes valores, que deberían fomentar un alejamiento del etnocentrismo que caracteriza nuestra sociedad actual (son mis valores los mejores y los demás son claramente inferiores).

Puede ocurrir algo similar en una partida a lo que muestra la galardonada Bailando con

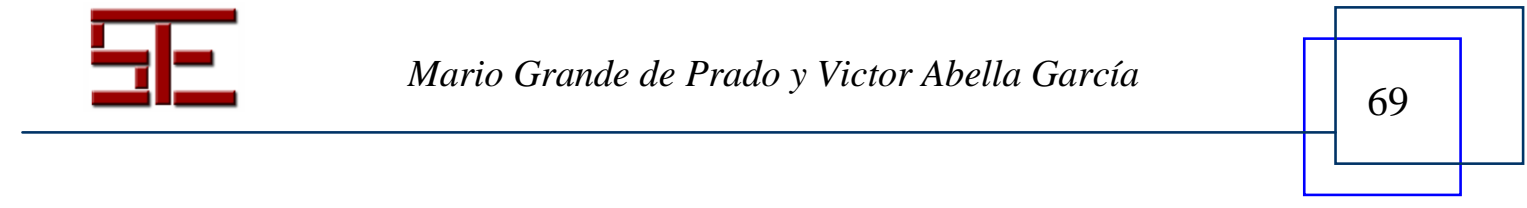




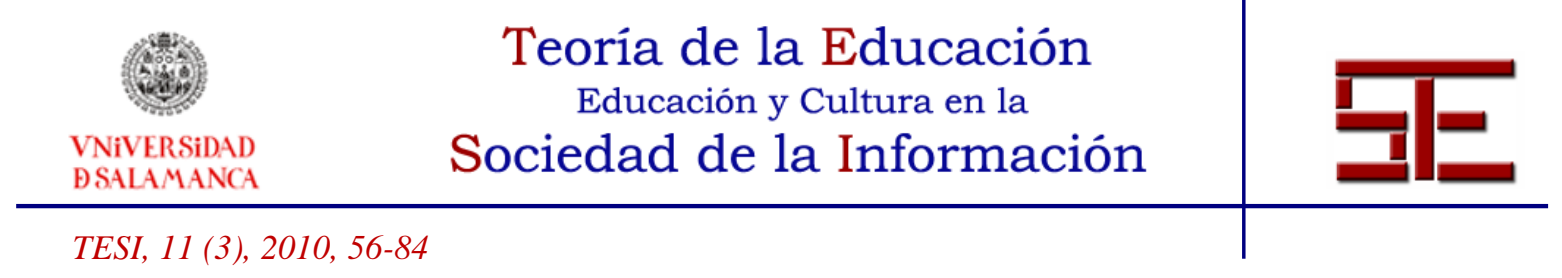

lobos una visión diferente de un colectivo (los indios americanos en este caso) tradicionalmente rechazado como inferior. Y si queremos algo más cercano a la cultura de nuestro país, el descubrimiento de América brinda la oportunidad de realizar algo parecido.

Evidentemente, los juegos de rol no son el Santo Grial, no transforman todo lo que tocan en algo extraordinario, sino que son un medio motivante y con unas características interesantes para profundizar en los valores, culturas, dilemas morales...

El cine también puede ser una herramienta interesante, pero eso no significa que todas las películas puedan ser aprovechables pedagógicamente.

Un ejemplo que vuelve a aunar cine y rol lo constituye la saga James Bond. Si las películas de James suelen ser machistas y violentas, el juego de rol puede serlo. Pero nadie impide a un director de juego realizar una partida en esa ambientación alejada de los estereotipos habituales. E incluso (con jugadores lo bastante maduros) puede realizarse un análisis crítico de la ambientación: jugarlo para comprender los valores que existen implícitamente. No estoy de todas formas demonizando ni el juego ni las películas en las que evidentemente se han introducido modificaciones con el paso de los años y que no dejan de ser hijos de su tiempo y sociedad, al igual que algunos autores de fantasía como Robert E. Howard, el creador de Conan o E. Rice Burroughs, el de Tarzán, influidos por el darwinismo social (Arsenal, 1999).

\section{6.- JUEGOS DE ROL y TICs}

En relación a las TICs (Tecnologías de la Información y la Comunicación) y estableciendo un paralelismo entre las TICs y los juegos de rol como algo externo que rompe la dinámica habitual del aula, son muy interesantes las reflexiones de Cebrián (Cebrián, 2001).

\section{1.- Posturas ante los juegos de rol}

Entre sus reflexiones se encuentran algunas ideas que bien podrían explicar la conducta de los docentes ante cualquier situación novedosa (Cebrián las muestra como reacción ante la televisión):

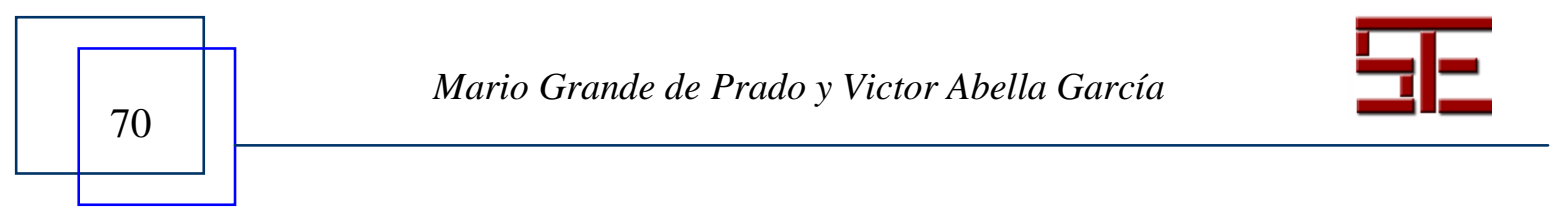




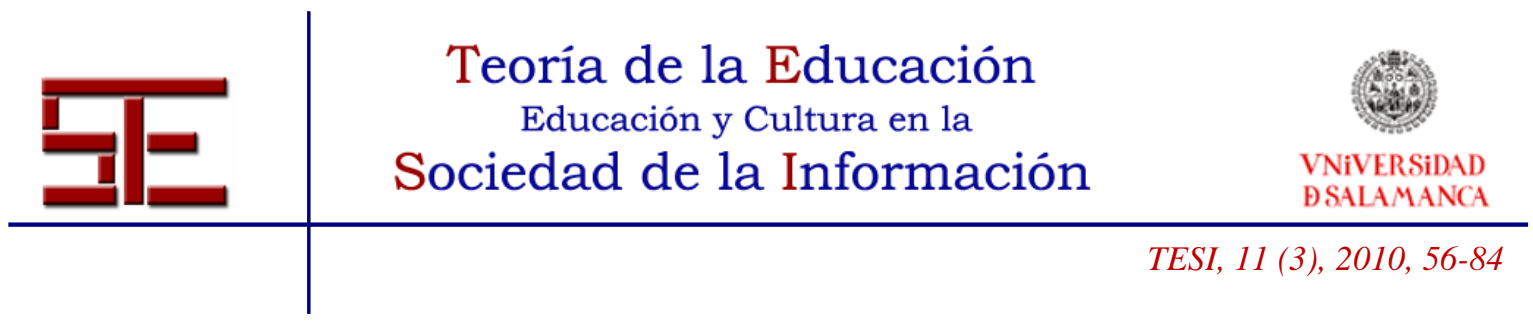

A) OPTAN POR INHIBIRSE

Los maestros deciden ignorar y obviar su existencia en el aula. Este comportamiento viene explicado por:

1. La falta de propuestas para esta etapa educativa proveniente de las instancias oficiales o editoriales educativas que pudieran guiar las acciones del maestro.

2. La carencia de sugerencias elaboradas dentro de los colegios

3. La concepción de los alumnos como incapaces de construir sus propios juicios.

4. La creencia sobre lo perjudicial que y su influencia en los escolares.

En la decisión de los maestros de no actuar influye, por tanto, la falta de experiencias conocidas sobre qué hacer.

\section{B) RECHAZAN}

Los educadores deciden suprimir, cortar y erradicar la presencia en el aula. Estas acciones están muy mediatizadas por la influencia en la infancia y por el desconocimiento hacia las ventajas educativas.

\section{C) MEDIAN LA PRESENCIA}

Los educadores deciden dar respuesta a cada una de las situaciones que se presentan en el aula.

Su experiencia docente, junto con el apoyo del equipo educativo, les lleva a utilizar algunas de las estrategias generales, comunes a cualquier otro tipo de actuación dentro del aula con los escolares, pero sin conocimiento de primera mano sobre los juegos.

\section{D) NEGOCIAN}

Deciden dar una respuesta más elaborada a la presencia en la escuela, planteándose hacer una inclusión directa y fuertemente implicada del tema en la programación docente, a través del desarrollo de proyectos de trabajo.

Evidentemente, esta última opción parece la más honesta y completa, al partir de los intereses de los alumnos y no interpretar la escuela como algo ajeno a su entorno.

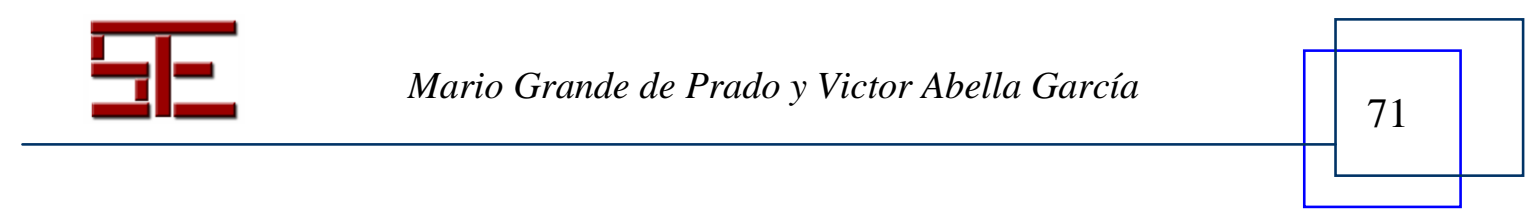




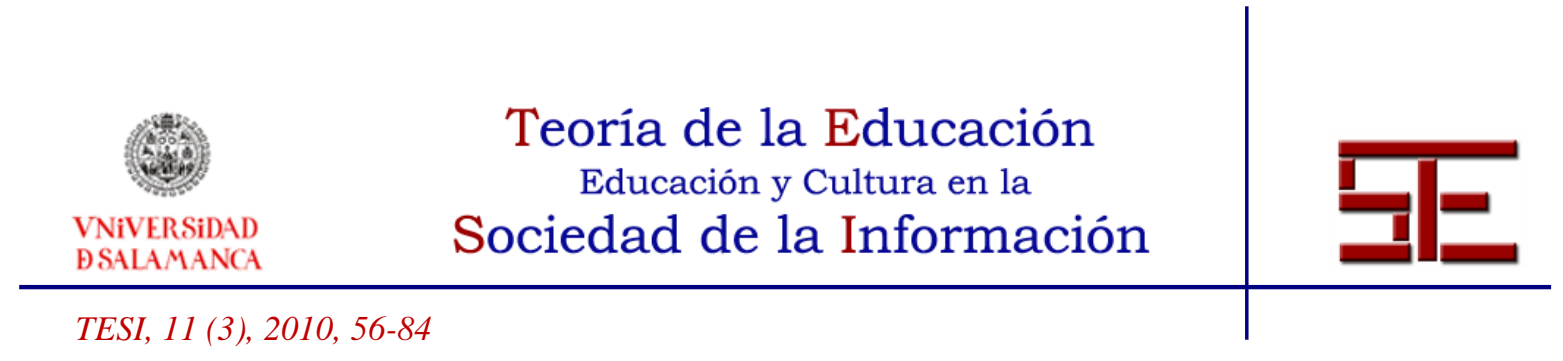

\section{2.- Videojuegos}

Dentro de las TICs, uno de los máximos impulsores de su difusión entre los jóvenes es el negocio del videojuego. Los videojuegos tienen en común con los juegos de rol varias características, como por ejemplo que son percibidos en general como algo pernicioso, se basan en simulaciones (en jugar a algo ficticio siendo agente activo) y son vistos como algo entretenido por los jóvenes que los practican...

La verdad es que estableciendo paralelismos entre los juegos de rol y los videojuegos desde el punto de vista didáctico, da la sensación de que muchas veces la escuela huye de aquellas cosas que le parecen divertidas, como si divertirse fuese incompatible con aprender. Focalizándose en los videojuegos, autores como Begoña Gros y el grupo F9 se han esforzado en señalar las ventajas didácticas de los videojuegos (Gros, 2006), y no hay que olvidar que muchos de ellos están inspirados en juegos de rol. También es justo indicar que algunas investigaciones han mostrado la existencia de valores discriminatorios o violentos en los videojuegos (Díez, 2007), siendo evidente que los videojuegos son productos de una sociedad con una serie de valores (no necesariamente siempre explícitos) que aparecen en dichos productos comerciales.

\section{7.- JUEGOS DE ROL EN EL AULA: PROPUESTAS}

Sobre la inclusión de los juegos de rol $^{3}$ dentro del aula, debemos plantearnos qué queremos hacer. ¿Usarlos como estrategia didáctica (jugando) o analizar lo ocurrido con ellos (reflexionando sobre percepciones, medios de comunicación...)?

En el segundo caso, podemos hablar sobre los medios de comunicación y su lectura crítica, se puede trabajar el tema de los juegos de rol, o sugerir como lectura para debate El diablo en el juego de rol (Martín, 2002), libro de lectura juvenil que si bien tiene un planteamiento positivo de los juegos de rol, transmite una sensación desconcertante al mezclarlos con el tarot y con acciones que exceden el juego de rol (allanamientos de morada, p. ej.).

En el caso de decidirnos valientemente por su uso, señala Pablo Giménez (Giménez, 2003) como apropiado el uso de los juegos de rol en talleres extraescolares o actividades fuera del aula (actividades libres por la tarde, fiestas, asociaciones de alumnos), ya que los JdR son actividades libres que necesitan un entorno más libre que una actividad en el aula de carácter obligatorio. Si optamos por su uso dentro del aula deberían buscarse

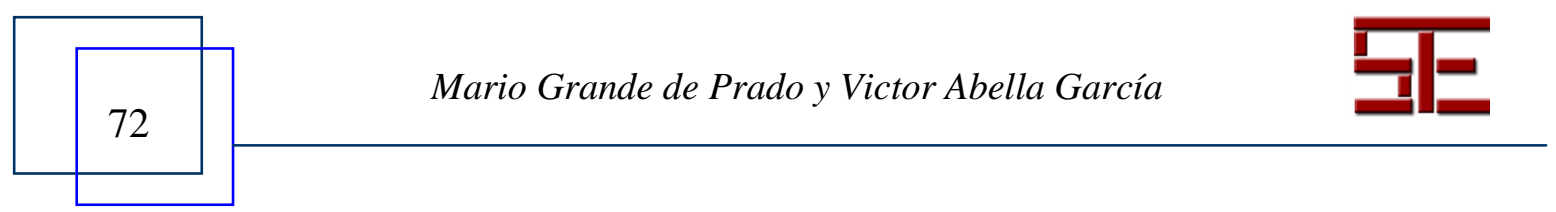




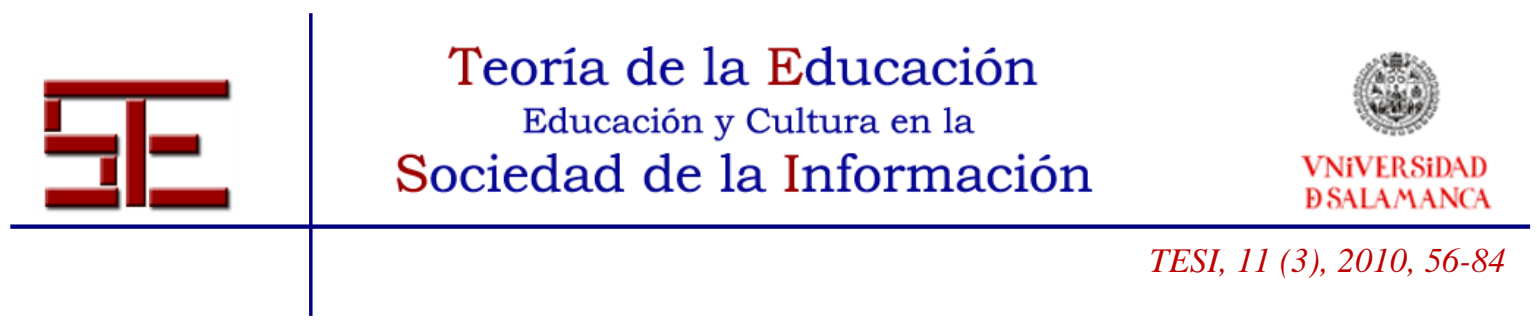

espacios y tiempos amplios de al menos una hora y media (además de estrategias atractivas o actividades opcionales para los que no deseen jugar). Bañeres sugiere las horas de tutoría (Bañeres, 2008) para los juegos de roles, tal vez en combinación con una hora de docencia que tenga el tutor si son seguidas puedan ofrecernos el margen temporal apropiado sin tener que realizar modificaciones en el horario habitual.

Podemos optar por:

a) Juegos de rol en vivo (más complicados de monitorizar, pero que permiten la participación de todo el grupo y que requieren varios monitores o ayudantes). Puede ser una opción algo compleja en caso de no haber jugado antes a la variante tradicional de mesa.

b) En el caso de jugar a ésta (la versión "de mesa"), el impedimento es gestionar una actividad pensada para grupos reducidos (de dos a seis) en grupo mayor (de hasta veinticinco). Las opciones pueden ser, dirigir una partida con un grupo de cuatro o cinco jugadores (tal vez manteniendo los personajes y cambiando los jugadores de sesión en sesión) mientras los demás observan (tal vez encargándoles observar a un personaje concreto o un aspecto de la partida). Puede ser apropiado en un grupo de no demasiados alumnos. Otra opción es jugar partidas simultaneas (bien la misma, bien partidas diferentes), por lo que es necesario contar con espacio para dividir el grupo de clase en cuatro o cinco subgrupos. Evidentemente, en grupos menores será más fácil (por ejemplo, en grupos de Programas de Cualificación Profesional Inicial).

¿Qué puede ocurrir en esas actividades? Como en muchas otras las buenas intenciones no necesariamente van a llevar a una actividad idílica. Al igual que un deporte puede fomentar el esfuerzo y el compañerismo o la competitividad más nefasta y actitudes antideportivas.

¿De qué manera podemos trabajar esto? Los juegos de rol tienen una ventaja importante: el jugador que dirige puede cambiar de partida a partida. Dentro del pequeño microgrupo que se forma, pueden surgir conflictos, pero si todos pasan por la experiencia de dirigir van a comprender más fácilmente que es un juego social en que todos deben colaborar para disfrutar. Si no es así probablemente el grupo no dure, al menos sin un cambio importante. Además, la mayor parte de los juegos se sustentan en la colaboración entre los miembros del grupo, lo que debería desembocar en una mayor empatía, tolerancia y actitud democrática.

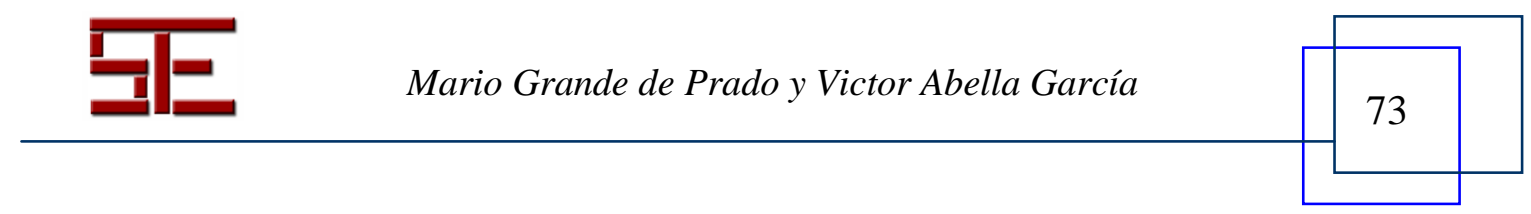




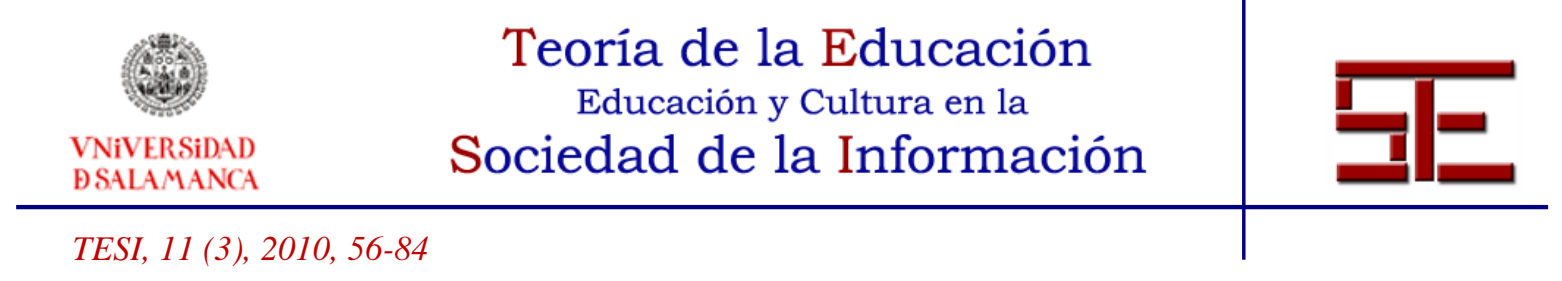

Una de las formas de utilizar en el aula los juegos de rol es mediante el método Lipman (Filosofía para niños) que guarda ciertas similitudes con el juego de rol. En este caso hay libros de lectura por edades que después suscitan debates, opiniones, valoraciones... Transformar este tipo de método en un juego de rol supone plantearse una serie de temas e irlos desgranando en la partida.

Utilizar los juegos de rol en el aula, al igual que en los cine fórums o con el uso didáctico de los vídeos, requeriría un trabajo previo y posterior (plantear cuestiones o lecturas previas, recoger reflexiones sobre la partida), examinando nuestros valores, prejuicios... y evidentemente (si nos ceñimos a los JdR tradicionales, "en mesa") un fraccionamiento de la clase de manera que cada grupo juegue con un director de juego (uno de los alumnos). Podría ser recomendable que estos directores de juego hubiesen jugado previamente la partida, un espacio amplio o varias clases adyacentes, así como un grupo no demasiado numeroso, sería recomendable.

Así mismo, tomando como referencia a Cebrián (Cebrián, 2001) y sus estrategias y recomendaciones sobre el uso del vídeo en educación (perfectamente aplicables a los juegos de rol) con alguna variación y las aportadas sobre juegos de roles por diversos autores (Muñoz, 2003; Bañeres, 2008; VV.AA., 2008), vamos a exponer una propuesta para el uso de los juegos de rol a nivel educativo.

\section{1.- Metodología y uso didáctico de los juegos de rol}

Muchos juegos de rol y partidas disponen de posibilidades educativas, es decir, que podemos realizar una "explotación didáctica" si elaboramos una adaptación a una realidad concreta. Para ello proponemos seguir cuatro pasos con algunas consideraciones a tener en cuenta:

a) antes de plantearlo en el aula

b) justo antes de jugar

c) durante el juego

d) después del juego

\section{A.- ANTES DE PLANTEARLO}

Lo primero que debemos hacer es conocer bien el juego y la partida.

También deberíamos elaborar una ficha para guardarla en nuestra base de datos que se

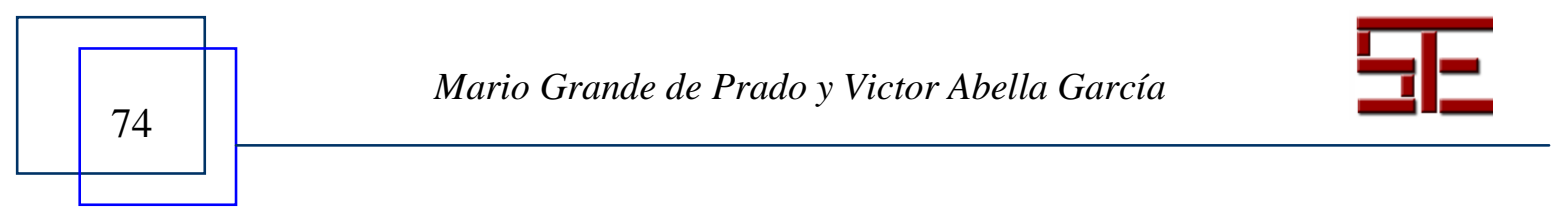




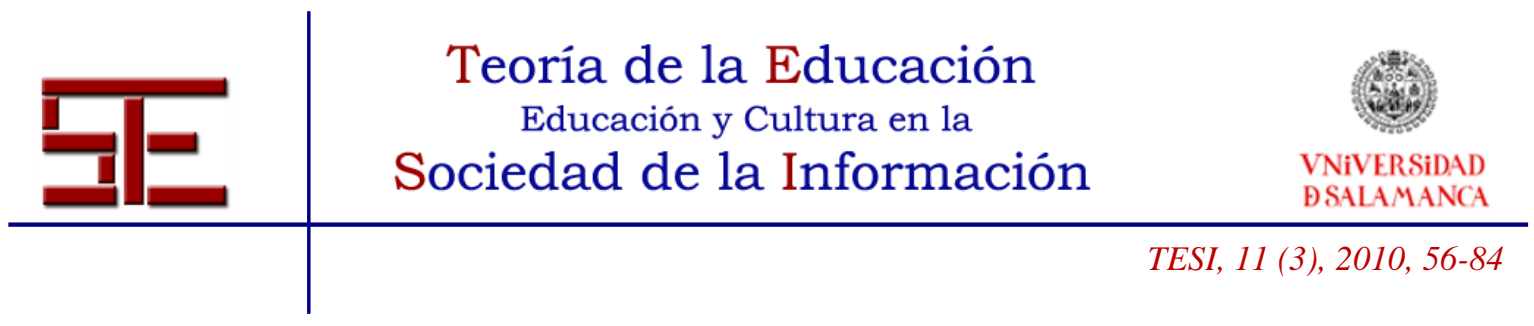

completará al final de los tres momentos, dado que debemos añadir las mejoras y las circunstancias reales una vez usado.

Igualmente, deberíamos realizar otras tareas como:

- Un mapa conceptual de los contenidos y conceptos más importantes.

- Planificar las actividades previas y posteriores que podemos realizar.

- Pensar qué objetivo va a desempeñar este juego dentro de la unidad didáctica que estamos trabajando en el aula.

- Seleccionar los fragmentos o secuencias que consideramos más importantes.

- Hacer cálculo del tiempo necesario y compararlo con el tiempo que tenemos.

- Disponer de un esquema de los contenidos.

- Elaborar fichas y materiales complementarios que tengan relación con la partida una vez acabado su visionado.

- Realizar un listado con las cuestiones que deseamos que se fijen, de las explicaciones y detalles que nos interesen, etc.

- Crear un clima favorable de confianza.

- Iniciarse (e iniciar al alumnado) en técnicas de simulación mediante juegos de roles sencillos.

- Comprender un sistema de juego sencillo y eficaz (existen muchos gratuitos, también sistemas genéricos desarrollados a nivel comercial).

- Comprender algunos de los recursos narrativos de los juegos de rol (disponibles en múltiples páginas y en casi todos los manuales de juegos de rol, de todas formas "Tras la pantalla" es una obra reseñable en este sentido por intención y contenido (Ramos, 2005).

- Seleccionar previamente si es preciso directores de juego y jugar con ellos la(s) partida(s) o revisarla(s).

\section{B.- EN CLASE, PERO ANTES DE SU VISIONADO}

Es posible que nos interese elegir varias estrategias, según la edad o conocimiento del tema por parte de los alumnos.

- Informar de lo que van a tratar los alumnos, ofreciendo alguna ficha de análisis.

- No adelantar nada, pidiendo que elaboren antes una ficha que pueda recoger la información desde los conocimientos que poseen.

- Realizar alguna actividad antes como lectura de libros, o visionados de

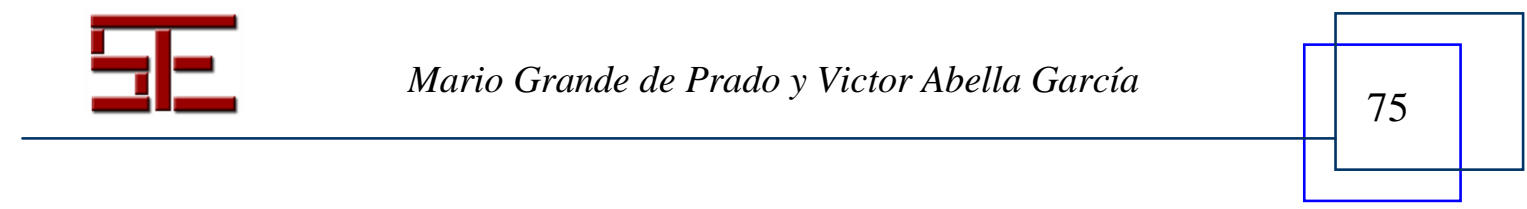




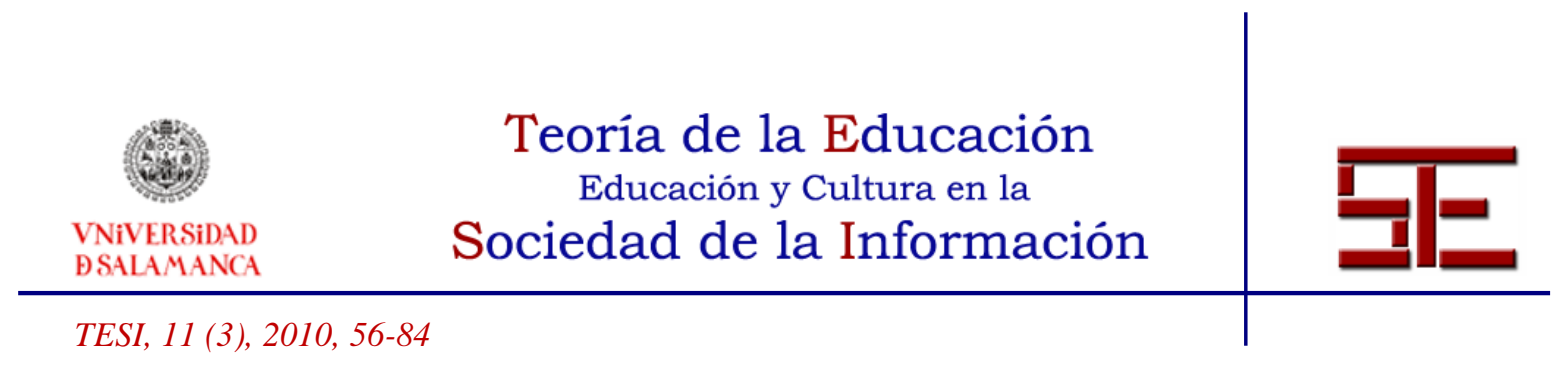

vídeos.

- Partir de las ideas que tienen con actividades como la lluvia de ideas sobre los conocimientos que poseen.

- Exponer al alumnado las bases generales del sistema de juego (es recomendable aquellos que permiten el uso de puntos para modificar el resultado de una situación al azar, ya que permiten a los jugadores un mayor peso en la narración de la historia).

- Considerar la posibilidad de elementos ambientales y decorativos (p.ej. música).

- Configurar grupos de juego (y observadores si es preciso).

\section{C.- DURANTE EL JUEGO EN CLASE}

Podrían aplicar las fichas de análisis que se han elaborado.

- Comentar o detectar aspectos relevantes o errores que hemos decidido analizar más adelante y con profundidad.

- Acostumbrarles a que recojan información resumida del contenido.

Lo que se pretende es que puedan realizar un análisis en profundidad.

\section{D.- DESPUÉS}

Podemos realizar el desarrollo del tema y de las demás actividades que tenemos pensadas o sobre el tema que estamos trabajando en clase.

- Exponer los resultados que todos hicieron con sus fichas y detectar errores.

- Realizar un resumen de los contenidos aprendidos, aclarar dudas. En suma, una síntesis para recordar.

- Realizar un mapa semántico y compararlo con el que hicimos anteriormente.

- Realizar alguna actividad para retener mejor la información obtenida, como ver un vídeo o realizar un mural resumen.

- Realizar actividades de preguntas, ejercicios, aplicaciones a otros ejemplos y situaciones, para conocer qué han aprendido o retenido.

- Realizar actividades para motivar la capacidad creadora y comprobar si han prestado atención y se han encontrado motivados.

- Realizar un comentario o debate sobre el tema central con ayuda de algunas cuestiones dadas por el profesor.

- Búsqueda de puntos de vista con otras personas que posean una opinión o

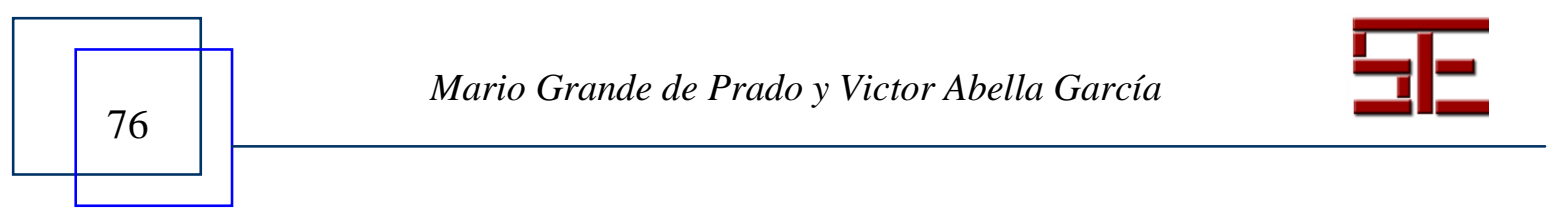




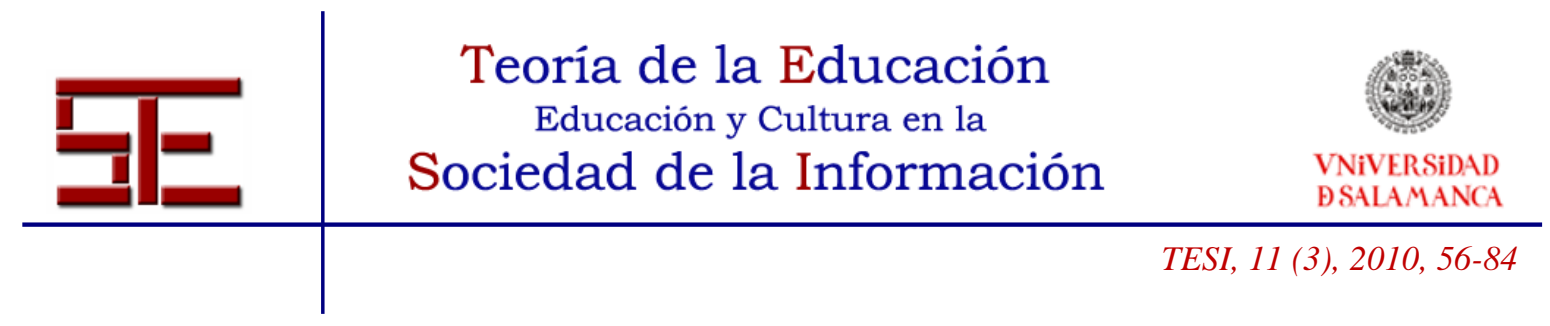

idea diferente sobre el tema.

- El docente debe comprobar y evaluar si con las actividades realizadas se han alcanzado sus objetivos, apuntando todas las mejoras y sugerencias en nuestra base de datos o ficha para posteriores aplicaciones.

- Realizar una valoración sobre el resto de jugadores (implicación y representación del personaje), de la trama y de la dirección de la partida.

- Buscar analogías con otras situaciones.

\section{2.- Estrategia de aplicación}

- Primer momento: Crear un debate a través de una dinámica de grupo recogiendo el docente un listado exhaustivo de las opiniones vertidas.

- Segundo momento: Partida que añade o profundiza en la información.

- Tercer momento: Debate analizando las ideas planteadas antes y los momentos de la partida que refuerzan o refutan nuestras ideas o concepciones.

\section{3.- Utilización activa de los JdR por los estudiantes}

Esto implica una mayor libertad de los alumnos para dirigir y organizar las partidas de rol. Las fases de utilización serían:

\section{A.- FASE DEL CONTRATO}

La realización es un trabajo de equipo, por lo que lo primero es negociar con los estudiantes los niveles y la profundidad de las responsabilidades que cada uno contrae con el equipo de trabajo, fomentando la voluntariedad (y ofertando trabajos en grupo alternativos si dividimos a la clase en grupos para que no todos tengan que jugar si no quieren).

\section{B. - DOCUMENTALISMO}

Partiendo de lo anterior y teniendo claro el objetivo, puede ser preciso buscar más información detallada y precisa sobre el tema. Esta tarea se puede repartir por grupos de alumnos:

a) Audio: recoger sonidos y efectos especiales, además de estudiar los tipos de música que sirvan para ambientar.

b) Texto: recoger distintas informaciones sobre el tema y elaborar un textoborrador para debatirlo en equipo, y tras las locuciones o grabado del texto por un locutor de entre el grupo, las preguntas y entrevistas del guión final.

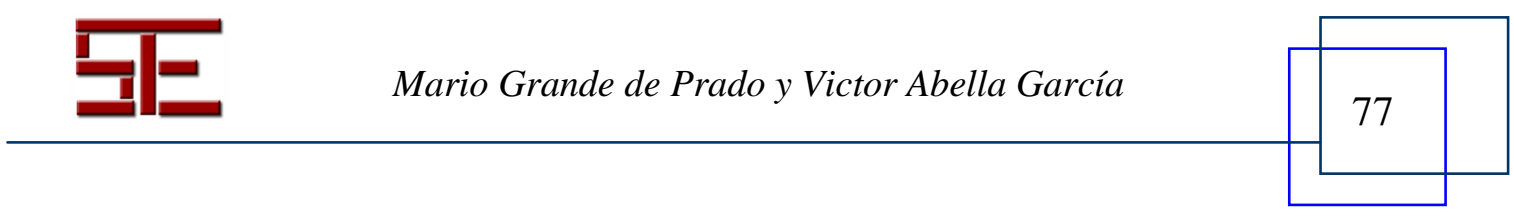




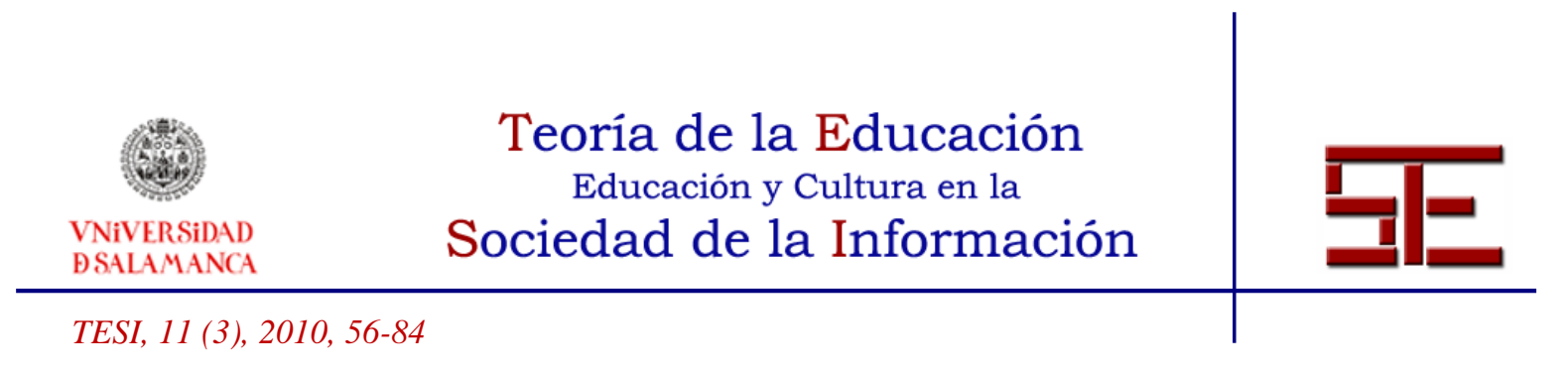

c) Imágenes: de interés.

d) Escoger un sistema de juego con los suplementos necesarios.

\section{C.- GUIONIZACIÓN}

Configurar de la partida, con tiempos, música, leitmotiv, relaciones de los personajes... (es recomendable que los personajes estén pregenerados, para ganar algo de tiempo).

\section{D.- JUEGO EN SÍ}

Quedar abierto para permitir una retroalimentación que favorezca adaptarse a los cambios durante el juego...

\section{E. - DEBATE POSTERIOR}

Buscando analogías, volviendo a los dilemas o temas tratados, preguntando a los alumnos sobre sus sensaciones durante el juego, qué les ha llamado la atención, tal vez proponiendo después pequeñas investigaciones o cazas del tesoro a través de Internet para solventar dudas...

Para terminar, en referencia a los JdR en el aula, Amnistía Cataluña (dedicada a la Defensa de los DDHH).http://www.amnistiacatalunya.org/, realiza estas consideraciones

El juego de rol en el aula:

- Los juegos de rol en el aula tienen un valor especial de cara a sensibilizar al alumnado respecto a los sentimientos y las perspectivas de otros grupos y la importancia de ciertos problemas.

- Conviene que los juegos de rol sean breves. Hay que disponer de tiempo suficiente para el debate que se realizará después: es fundamental que los alumnos/as puedan expresar libremente sus sentimientos, temores y opiniones después de la actividad con el fin de aprovechar al máximo las lecciones más positivas y disipar las sensaciones negativas que se hayan podido experimentar.

- El profesorado debe procurar que los alumnos/as no se identifiquen demasiado con su papel.

- Conviene que los participantes mantengan una cierta distancia con el papel que ocupan, haciendo por ejemplo observaciones o preguntas.

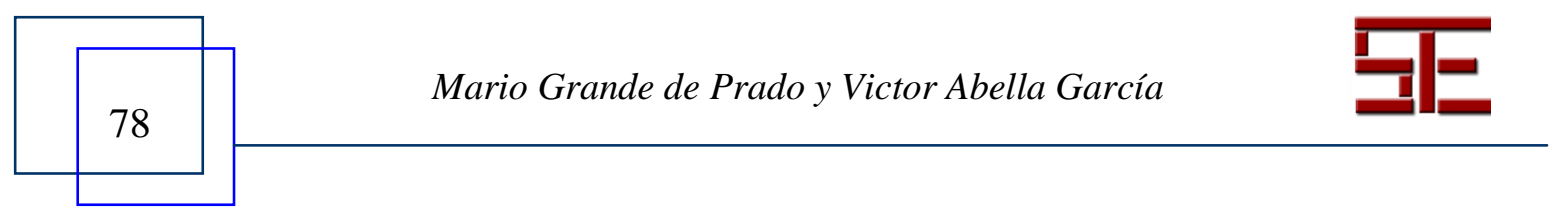




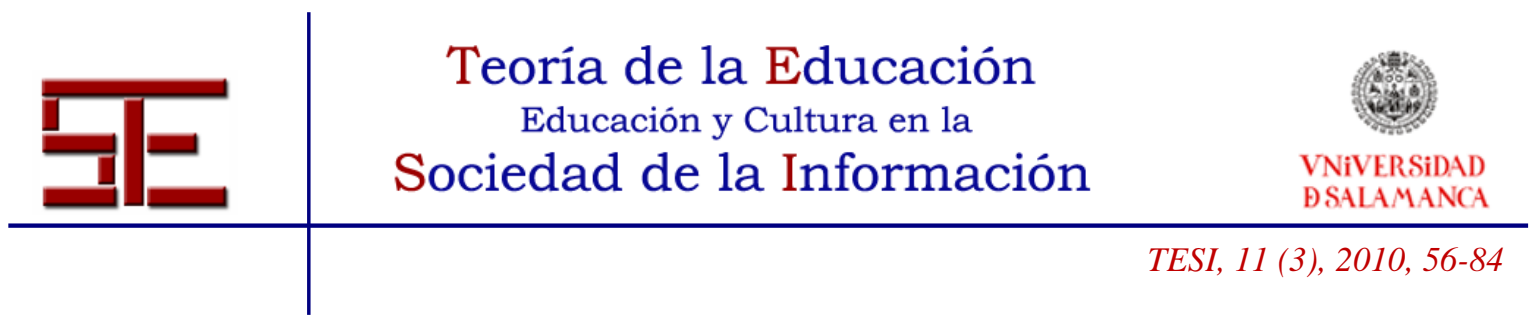

\section{8.- CONCLUSIONES}

Como hemos visto, los juegos de rol poseen múltiples aplicaciones en el aula, trabajo en equipo, educación en valores, fomento de la lectura... tal y como muestran los artículos relacionados más relevantes.

Además hemos realizado algunas propuestas sobre su aplicación, incidiendo especialmente en los dilemas morales y en una serie de sugerencias sobre su posible utilización en el aula, inspiradas estas últimas en las estrategias empleadas en los juegos de roles y en las TICs. Con los recursos apropiados el juego de rol puede convertirse en una herramienta lúdica que, correctamente empleada, nos ayuda en la difícil tarea de la educación en valores, siempre que seamos capaces de superar los mitos que rodean estos juegos de manera claramente injusta.

\section{9.- BIBLIOGRAFÍA}

Abad Pascual, J. J. (2008). Educación ético-cívica. Madrid: McGraw-Hill.

Amnistía Cataluña (2009). El juego de rol en el aula. Disponible online.

Extraído el 20 de abril de 2009 de http://www.amnistiacatalunya.org/.

Arsenal, L. (1999). Conan, un estudio del mito. Madrid: Metrópolis Milenio.

Bañeres, D. (2008). Adolescentes y juegos de rol. En Domènec, B. (coord.), Estrategias didácticas (pp. 125-130). Barcelona: Grao.

Calleja, S. (1995). Juegos de Rol y Literatura. CLIJ, Cuadernos de Literatura Infantil y Juvenil, 73, 7-17

Cantón Mayo, I. (2001). Nueva organización escolar en la sociedad del conocimiento. Bordón, 53 (2), 201-213.

Castell, M., (1997). La era de la información. Economía, sociedad y cultura. Vol. 1. La Sociedad Red. Madrid, Alianza.

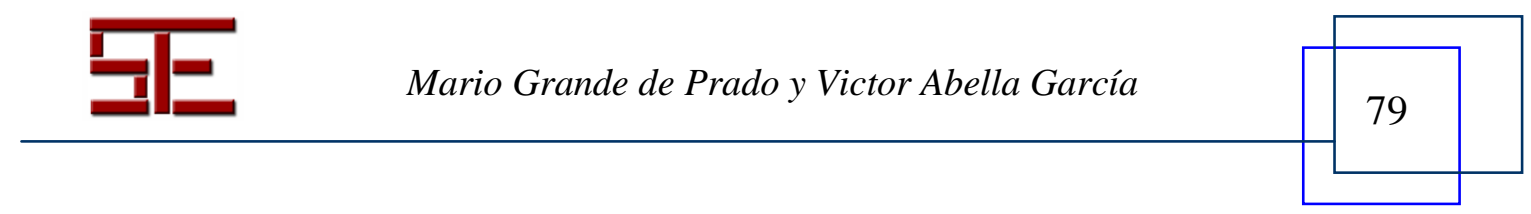




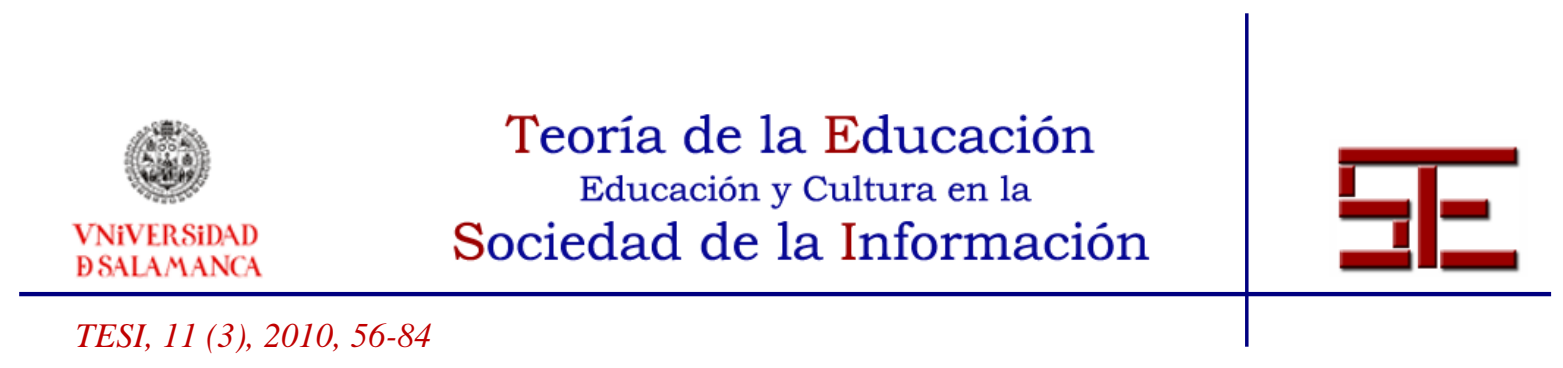

- (2001). La dimensión cultural de Internet. Disponible online. Extraído el 10 de octubre de 2009 de

http://www.uoc.edu/culturaxxi/esp/articles/castell0502/castell0502.html

Cebrián de la Serna, M. (2005). Tecnologías de la información y comunicación para la formación de docentes. Madrid: Pirámide.

Díaz Sacaluga, I. (2006). Unidad Beta: Superhéroes en la Segunda Guerra Mundial. Madrid: NSR.

Díez Gutiérrez, E. J. (2007). El género de la violencia en los videojuegos y el papel de la escuela [Versión electrónica].Revista de Educación, n³42, 127-146. Disponible online en

http://www.revistaeducacion.mec.es/re342/re342_07.pdf)

García Ciriero, R., Amarilla Pérez, J. C. \& Roviera Serna, C.M. (2010). El juego de rol en vivo como herramienta didáctica. Tádem: Didáctica de la educación física, $\mathrm{n}^{\circ} 34,8$ 22. Barcelona: Grao.

Garín, M. \& Pérez, O. (2009). Entre mundos e historias: ciencia ficción y experiencia de juego. Formats, Revista de Comunicación Audiovisual, nº5. Barcelona: Universidad Pompeu Fabra.

Giménez, P. (2003). Hacia una propuesta pedagógica de los juegos de rol [Versión electrónica]. Primeras noticias. Revista de literatura, $\mathrm{n}^{\circ}$ 195, 81-84.

Gros, B. (2008). Videojuegos y aprendizaje. Barcelona: Grao.

Homo Ludens. Definición de juegos de rol (2001). www.homo-ludens.com http://homoludens.iespana.es/

Ibáñez, R. (1989). Campaña de La Llamada de Cthulhu, La Bestia no debe nacer [Versión electrónica]. Líder, nº 12-16. Barcelona: Joc Internacional

Izquierdo, D. (2010). El juego de rol como instrumento psicopedagógico para la

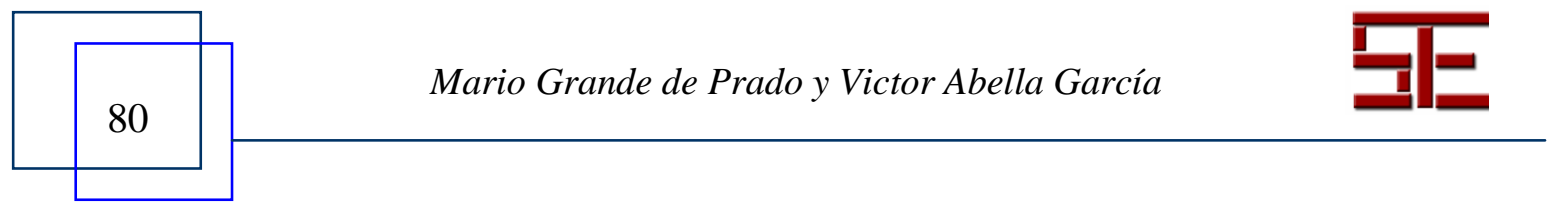




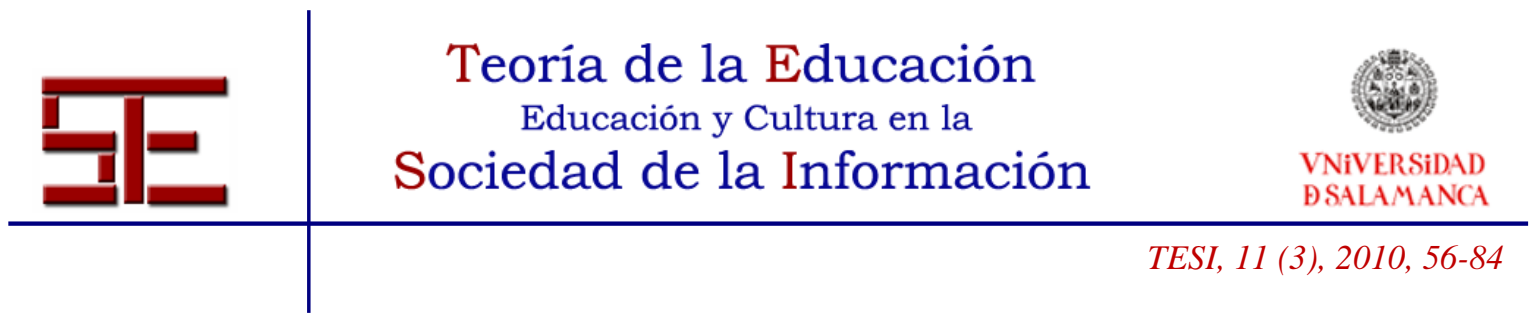

exploración y comprensión de la identidad sexual y de género. Tándem: Didáctica de la educación física, $\mathrm{n}^{\circ}$ 34, 64-74. Barcelona: Grao.

Jiménez, M., Caballero, P. \& Tinoco, M. (2010). Los valores humanos de los superhéroes. Tándem: Didáctica de la educación física, n 34, 33-46. Barcelona: Grao.

Jodar, A. E. \& Vecina Jiménez, M. L. (1999). Efectos psicológicos de los juegos del rol en el desarrollo social y cognitivo de los menores. En VV.AA., 1999 Estudios e investigaciones. Madrid: Defensor del Menor. (Disponible online en http://dreamers.com/defensadelrol/articulos/psicologos.htm)

Kohlberg, L. (1992). Psicología del desarrollo moral. Bilbao: Editorial Desclée de Brower.

Kramer, F. (2002). Manual práctico de educación ambiental: técnicas de simulación, juegos y otros métodos educativos. Madrid: La Catarata.

Marcano, B. (2008). Juegos serios y entrenamiento en la sociedad digital. Teoría de la Educación: Educación y Cultura en la Sociedad de la Información, vol. 9, n³. Salamanca: Universidad de Salamanca.

Martín, A. (2002). El diablo en el juego de rol. Madrid: Edelvives.

MEC. (2009). Los juegos de rol. Disponible en http://www.isftic.mepsyd.es/w3/recursos2/estudiantes/ocio/op_03.htm\#03

Muñoz, A. (2003). El juego de rol como recurso metodológico para la resolución de conflictos escolares. En Vinyamata, E. (coord.), Aprender del Conflicto. (pp. 95-110). Barcelona: Grao.

ONU (2009). Webcast de 17 de marzo, Galáctica en la ONU. Disponible online. Extraído el 10 de mayo de 2009 de hptt://www.un.org/webcast/2009.html.

Ortiz Castells, J. (1999). Juegos de rol e identidades inventadas. Cuadernos de Pedagogía, $\mathrm{n}^{\circ}$ 285, 61- 67. Barcelona: Praxis.

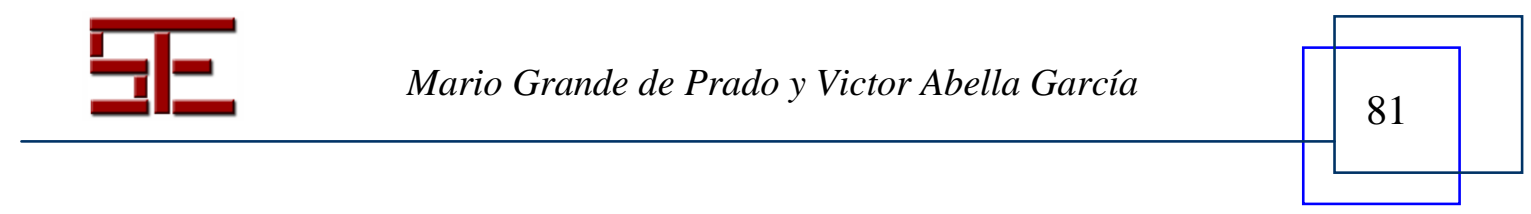




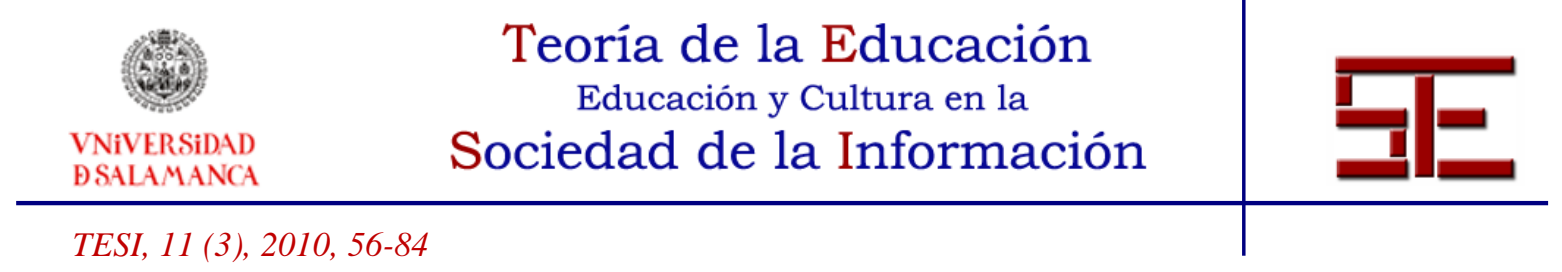

Parra, M., Caballero, P. \& Domínguez Carrillo, G. (2010). La conquista del imperio romano. Tándem:Didáctica de la educación física, n³4, 47-63. Barcelona: Grao.

Paulos, J. A. (1988). Innumeracy: Mathematical Illiteracy and Its Consequences. New York: Hill and Wang.

Pérez López, I. J., Delgado, M \& Rivera García, E. (2009). Efectos de un juego de rol en los conocimientos acerca de la actividad física y la salud en Educación Secundaria. Revista de Educación, nº 349, 481-496. Madrid: Ministerio de Educación.

Pérez Reverte, A. (1994). Homo Ludens. El Semanal, 26 de junio de 1994.

Ramos, P.J. (2005). Tras la pantalla. Madrid: NSR.

- (2008). Eyes Only. Madrid: NSR.

Rokeach, M. (1979). Understanding human values. New York: The Free Press.

San Sebastián I. y San Sebastián J. (2004). ¿A qué juegan nuestros hijos?. Madrid: La Esfera de los Libros.

Taylor, J. L. (1995). Guía de simulación y de juegos para la educación ambiental. Bilbao: Los Libros de la Catarata.

Tizón, R. (2006). Creer lo increíble: Mitos y verdades sobre los juegos de rol. Madrid: NSR.

VV.AA. (1993). Guía de los Juegos de rol. Barcelona: Ediciones Zinco.

VV.AA. (1999). El accidente minero de Aznalcóllar. Juego de simulación de roles. Sevilla: Consejerías de Medio Ambiente y de Educación y Ciencia. Junta de Andalucía. Sevilla. Disponible online. Extraído el 25 de septiembre de 2007 de http://www.juntadeandalucia.es/averroes/publicaciones/valores/aznalcollar.pdf.

VV.AA. (2001). Pasajes. Un juego de sensibilización sobre la realidad de los refugiados. Madrid: ACNUR. Disponible online. Extraído el 5 de mayo de 2002 de http://www.unhcr.org/publ/PUBL/473dc1772.pdf.

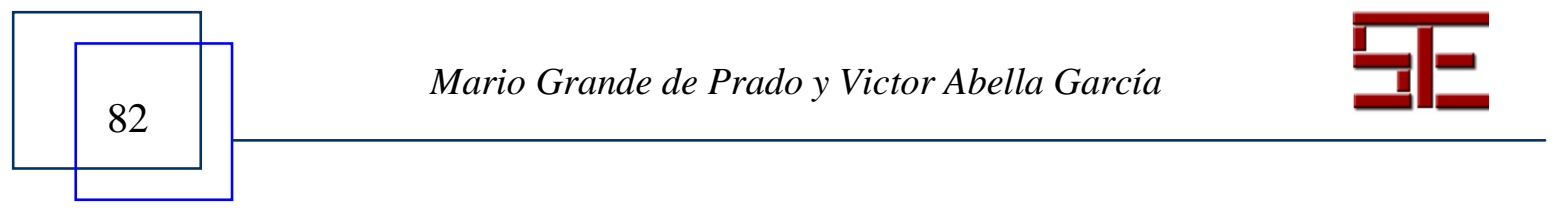




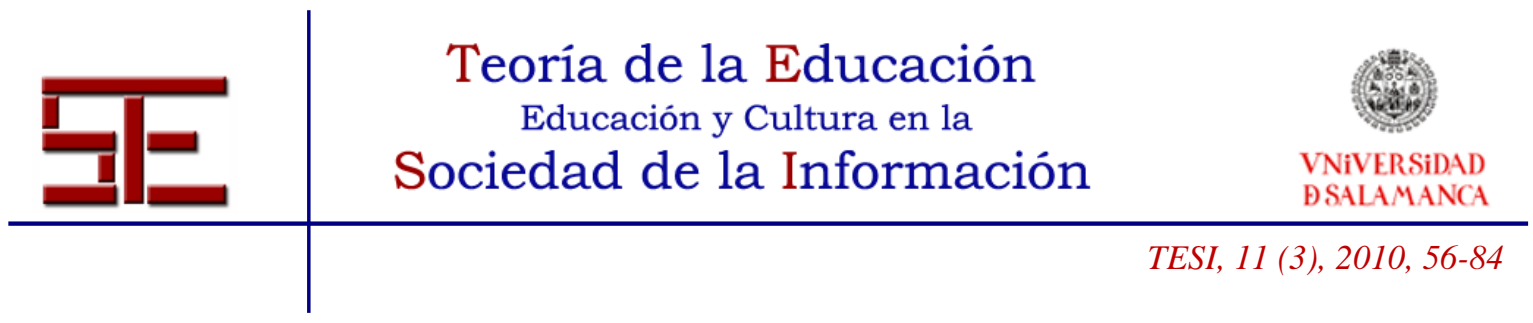

VV.AA. (2008). Los modelos sociales de enseñanza: el juego de roles. Escuela, n³ (monográfico). Madrid: Wolters Kluwer.

VV.AA. (2009). Cuando jugar se convierte en un problema: el juego patológico y la adicción a los juegos de rol online. Aloma: revita de psicologóa, cieéncies de léducació i de lésport, $\mathrm{n}^{\circ}$ 25, 201-220. Barcelona: Universitat RamónLlul.

VV.AA. (2010). Unamix: de la ficción a la realidad educativa. Tándem: Didáctica de la educación física, n³4, 23-32. Barcelona: Grao.

Webcast de 17 de Marzo, Galáctica en la ONU (2009) Disponible en http://www.un.org/webcast/2009.html.

\section{NOTAS}

1 Mención especial, y en mi opinión bastante representativa del sensacionalismo periodístico que ha rodeado a los JdR lo encontramos en "¿A qué juegan nuestros hijos?" (San Sebastián y San Sebastián, 2004, 155-178), en el cuál analizan "los incontrolables juegos de rol" (así aparecen citados en la contraportada) mediante la observación de cuatro o cinco partidas de un grupo de jugadores. Al igual que el informe Pulling en EE.UU. (Tizón, 2006) evoca un número ingente de miedos sin ninguna base científica. Aun así, realiza recomendaciones generales razonables: qué los padres sepan qué hacen sus hijos y que la edad mínima se sitúe en los doce años (similares a las realizadas en el estudio del defensor del menor [VV.AA., 1999] y a lo que cualquier persona con sentido común considera que debería conocer un buen padre).

2 Directores de juego, árbitros o narradores, son los encargados de:

- Describir situaciones de la historia.

- Describir a otros personajes.

- Actuar de árbitro de las reglas.

- Parar el juego cuando ya sea demasiado tarde, alguien tenga que irse o alguien quiera irse" (Homo Ludens. 2001).

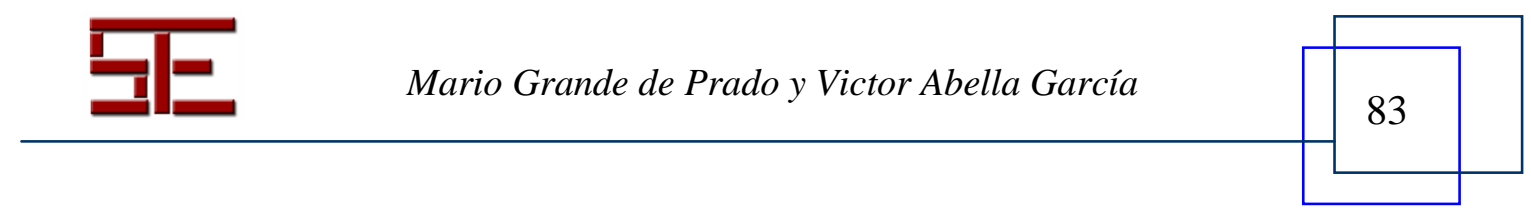




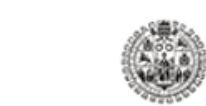

Teoría de la Educación

Educación y Cultura en la

VNiVERSIDAD
DSALAMANCA

Sociedad de la Información

TESI, 11 (3), 2010, 56-84

3 Más datos sobre los juegos de rol en la Guía de los juegos de rol (VV.AA., 1993) o en Tras la pantalla (Ramos, 2006) en la página de la extinta asociación nacional "Homo Ludens" http://homoludens.iespana.es/ (con juegos de rol sencillos y gratuitos) o lógicamente en cualquier juego de rol (como el reciente NSd20).

Para citar el presente artículo puede utilizar la siguiente referencia:

Grande de Prado, M. (2010). Los juegos de rol en el aula, en Orejudo González, J.P. (Coord.) Perspectiva educativa y cultural de "juego de rol". Revista Teoría de la Educación: Educación y Cultura en la Sociedad de la Información. Vol. 11, nº 3. Universidad de Salamanca, pp. 56-84 [Fecha de consulta: dd/mm/aaaa].

http://campus.usal.es/ revistas_trabajo/index.php/revistatesi/article/view/7450/7466 